\title{
El papel del inventario ambiental exhaustivo en el proceso de la configuración definitiva de la Infraestructura Verde del litoral sur de la Comunitat Valenciana
}

The role of the exhaustive environmental inventory in the process

of the definitive configuration of the green infrastructure of the southern coast of the Comunitat Valenciana

\author{
Ascensión Padilla Blanco \\ ma.padilla@ua.es
}

Antonio Prieto Cerdán

a.prieto@ua.es

Juan Antonio Marco Molina

ja.marco@ua.es

\section{Pablo Giménez Font}

pablo.gimenez@ua.es

Ángel Sánchez Pardo

a.sanchez@ua.es

Departamento de Análisis geográfico regional y Geografía física

Universidad de Alicante (España) 


\title{
Resumen
}

La urbanización en el sur del litoral alicantino ha supuesto la eliminación y la fragmentación del hábitat de taxones de gran interés, catalogados y clasificados como amenazados, caso de Helianthemum caputfelis Boiss. y Tudorella mauretanica Pallary. Para conocer el estado legal de protección y la distribución de estas especies se ha consultado la información disponible en organismos públicos estatales y autonómicos. Además, se han añadido los datos tomados por los autores con GPS de alta precisión desde 2006. Esta información corológica ha permitido elaborar un análisis espacial con herramientas SIG y valorar el estado actual de estas especies en el sur de la provincia de Alicante. En este trabajo, se pone de manifiesto cómo la información exhaustiva y detallada ha permitido u obligado a rediseñar sucesivos instrumentos de planificación; siendo la Infraestructura Verde el concepto utilizado para la configuración definitiva de los espacios protegidos mediante la aplicación del criterio básico de conectividad ecológica.

Palabras clave: Helianthemum caputfelis Boiss; Tudorella mauretanica Pallary; taxones amenazados; DGPS; cartografía corológica.

\begin{abstract}
The urbanization in the south coast of Alicante has meant the elimination and fragmentation for the habitat of very interesting taxa specimens, cataloged and classified as threatened, in the case of Helianthemum caput-felis Boiss. and Tudorella mauretanica Pallary. In order to know the legal status of protection and the distribution of these species, the information available in state and autonomous public agencies has been consulted. In addition, the data taken by the authors with high precision GPS since 2006 has been added. This information has allowed to elaborate a spatial analysis with GIS tools and to assess the current status of the two species in the south of the province of Alicante. In this paper, it becomes clear how the exhaustive and detailed information of these two threatened species has allowed or forced to redesign successive planning instruments; being the Green Infrastructure the concept used for the definitive configuration of protected spaces through the application of the basic criterion of ecological connectivity.
\end{abstract}

Key words: Helianthemum caputfelis Boiss; Tudorella mauretanica Pallary; threatened taxon, DGPS; GIS.

\section{Introducción}

Dentro de la política de Paisaje que se viene desarrollando en la Comunitat Valenciana desde 2004, la definición de la Infraestructura Verde es uno de sus principales objetivos. La legislación valenciana, en la ya derogada Ley 4/2004, de 30 de junio, de Ordenación del Territorio y 
Protección del Paisaje (LOTPP), la concibe como una red interconectada formada por los paisajes de mayor valor ambiental, cultural y visual, como parte de la estructura ecológica de la región, cuyo fin último es el de mantener la calidad de vida, la biodiversidad y los procesos ecológicos básicos. En este sentido, resulta decisiva su definición multiescalar, es decir, tanto a nivel regional como comarcal y municipal, para conseguir la sostenibilidad territorial a largo plazo a todos los niveles. Así, una de sus principales herramientas de gestión es la conservación de los hábitats, las especies y los elementos naturales estructurantes. Esta definición se refuerza con la vigente Ley 5/2014, de 25 de julio, de Ordenación del Territorio, Urbanismo y Paisaje (LOTUP), en la que se considera como aspecto obligatorio en el planeamiento municipal, donde cada uno de estos elementos han de ser objeto de zonificación y regulación de manera previa a la planificación del resto de usos, residenciales, dotacionales y económicos, con el fin de crear una estructura coherente con la Infraestructura Verde y potenciar los valores naturales, paisajísticos y calidad de vida del municipio; se constituye como la referencia para estructurar las decisiones de planificación de usos, de modo que debe integrarse en todos los sectores y zonas de la ciudad (Cantó, 2014).

La Infraestructura Verde se conceptúa como conector de zonas protegidas o de alto valor natural, de espacios verdes urbanos y rurales, así como de elementos urbanos, zonas verdes y espacios libres públicos que sirvan de corredores ecológicos. Como bien indica Feria y Santiago (2017, p. 137) la conectividad es, por tanto, un principio fundamental. Ya en el Decreto 120/2006, de 11 de agosto, del Consell, que aprobaba el Reglamento de Paisaje, aparecía esta concepción en la figura del Sistema de Espacios Abiertos, definido, independientemente de su clasificación o calificación urbanística, con un régimen de uso y ordenación estructural, como:

conjunto integrado y continuo de espacios en general libres de edificación, de interés medioambiental, cultural, visual, recreativo y las conexiones ecológicas y funcionales que los relacionan entre sí.

Este fue el precedente que dio lugar a las disposiciones legales con la actual definición de la Infraestructura Verde en la línea de las directrices de la Unión Europea (Estrategia de la Unión Europea de 2013 y la Agenda Territorial Europea 2020), como la conexión ecológica y funcional de los espacios de interés ambiental, cultural y paisajístico que quedó regulada mediante la ley 12/2009, de 23 de diciembre de medidas fiscales, de gestión administrativa y financiera, y de organización de la Generalitat que, a su vez, modificaba la originaria en el capítulo XIII: de la modificación de la ley 4/2004, de 30 de junio, de ordenación del territorio y protección del paisaje.

El desarrollo urbanístico del litoral ha determinado la reducción notable de hábitats de interés y de la biodiversidad en la Comunitat Valenciana, donde, según el Informe de Evaluación de los Ecosistemas del Milenio en España, el aumento de las zonas urbanizadas y áreas ocupadas por 
otras actividades económicas fue del 95,1\% entre 1987 y 2005 (MAGRAMA, 2011). Para el caso concreto de la provincia de Alicante, ésta se encuentra entre las diez más pobladas de España y presenta los mayores crecimientos de población en los últimos quince años, concentrada fundamentalmente en el litoral (Prieto, 2009). Además, del volumen de turistas que visitan anualmente la provincia, 13,5 millones en 2017, la mayor parte también se concentran en este sector (Agencia Valenciana del Turisme, 2018).

Si bien el atractivo turístico alicantino puede residir fundamentalmente en el binomio "sol-playa", en los últimos años se ha promovido desde la administración otro tipo de turismo que busca la riqueza ambiental y paisajística (Vera \& Baños, 2010). Se ha observado y constatado que la ocupación descontrolada del litoral y la desaparición de hábitats naturales de interés redunda negativamente en la economía, ya que ese otro tipo de turista rechaza un litoral totalmente urbanizado y deja de visitar nuestras costas (Vera Rebollo et al., 2009). Pero esto puede enmascarar otra realidad y es la denominada naturbanización, es decir, que espacios con atractivo natural, poco a poco, sean absorbidos por el desarrollo urbanístico y se desencadenen impactos negativos (Capdepón Frías, 2016: 35). De ahí que la solución planteada sea la de crear y promover una gestión integrada de las áreas litorales (2011/235 Decreto 1/2011, de 13 de enero, del Consell, por el que se aprueba la Estrategia Territorial de la Comunitat Valenciana), en la que se tengan en cuenta la protección, la conservación, pero también aspectos sociales y económicos; por supuesto, dentro de un marco de desarrollo sostenible.

No hay que olvidar que las costas bañadas por el Mar Mediterráneo constituyen una de las zonas del planeta calificadas como "Biodiversity hotspot" (Myers et al., 2000), con un elevado número de especies catalogadas como endémicas. Precisamente, ocupan esa estrecha franja terrestre en la que se da el ya mencionado proceso de consolidación urbana descontrolada, lo que incrementa su vulnerabilidad y peligro de extinción (Such Climent, 1995; Padilla \& Such, 2001; Capdepón Frías, 2016). Por otra parte, la aplicación de la Ley 2/2013 de 29 de mayo de protección y uso sostenible del litoral y de modificación de la Ley 22/1988 de 28 de julio de Costas, lejos de incrementar la protección, puede suponer una mayor privatización y alteración del medio litoral alicantino al detraer bienes que antes estaban integrados en el Dominio Público Marítimo Terrestre (DPMT), afectando negativamente no solo a la pérdida de biodiversidad, sino también a su valor como patrimonio natural, en el que se incluye su riqueza litológica, geológica y geomorfológica (Padilla \& Such, 2016).

En los últimos cuarenta años se ha producido una gran transformación de los usos del suelo en el litoral alicantino de forma paralela al incremento de las actividades turísticas (Gaja \& Díaz, 2006; Martí \& Nolasco, 2011). Se han ocupado amplios sectores agrícolas y naturales por urbanizaciones residenciales, provocando la progresiva fragmentación de los hábitats de interés comunitario y 
aislando poblaciones de diversas especies, con graves consecuencias para su viabilidad natural. Es el caso de dos endemismos de flora y fauna excepcional: Helianthemum caput-felis Boiss. y Tudorella mauretanica Pallary (Figura 1) que comparten hábitat en el tramo litoral de los municipios de Torrevieja, Orihuela y Pilar de la Horadada, en el extremo meridional de la provincia de Alicante.

Figura 1. Helianthemum caput-felis Boiss. y Tudorella mauretanica Pallary

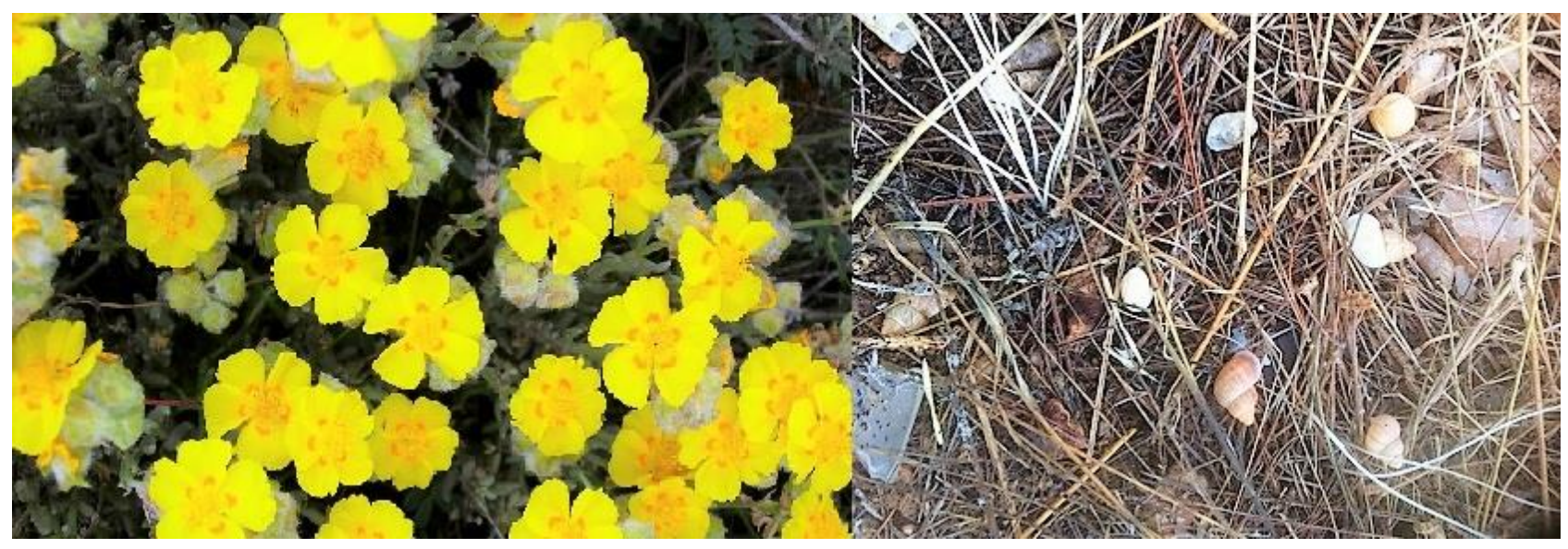

Fuente: elaboración propia, archivo fotográfico MedSPai

Helianthemum caput-felis Boiss., también denominada popularmente como jarilla cabeza de gato o setge cap de gat debido a la similitud del cáliz cerrado a este felino, es un caméfito sufruticoso o arbusto leñoso heliófilo con una fisonomía redondeada y que no supera los 30-40 centímetros de altura (Mateo \& Crespo, 2003, p. 96; Banco de datos de la Biodiversidad de la Generalitat Valenciana; Servei de Vida Silvestre, 2006). Respecto a Tudorella mauretanica Pallary se trata de un molusco o gastrópodo con una concha dura de color anaranjado o amarillento con 4-5 vueltas de espira muy marcadas o profundas y un opérculo grueso y calcáreo muy característico (Verdú et al., 2011, pp. 1225-1231; BDB-Conselleria de Medi Ambient, Aigua, Urbanisme i Habitatge).

Ambas especies se distribuyen por las costas mediterráneas, pero, pese a que su área de distribución pueda parecer amplia, su ubicación es puntual y, para el caso de la península ibérica, se trata de poblaciones poco numerosas. Por ello, Tudorella mauretanica Pallary está catalogada a nivel nacional como "en peligro" (EN) y en el autonómico como "vulnerable" (VU) y Helianthemum caput-felis Boiss. como "en peligro" (EN), en ambos. Las dos especies están protegidas espacialmente por la figura legal valenciana de las microrreservas vegetales de flora, aunque las superficies rondan desde valores inferiores a la hectárea hasta aproximadamente las siete hectáreas.

La plasmación de la filosofía de la Infraestructura Verde en el litoral alicantino debería de reforzar la protección a escala de detalle, es decir, la que concierne a estas especies amenazadas. Por este motivo, es fundamental elaborar un inventario ambiental exhaustivo, como se presenta en este 
artículo, que sea de consulta pública y obligatoria a la hora de realizar cualquier actuación territorial; de este modo, la protección sí sería efectiva. Por lo tanto, los objetivos de esta investigación son presentar el estado actual de conservación y protección, así como la distribución espacial, de estas dos especies amenazadas en el sur de la provincia de Alicante; poner de manifiesto que la superficie protegida actual no es suficiente para reducir la fragmentación de sus poblaciones y de los hábitats en los que se insertan; y resaltar la necesidad de una cartografía oficial corológica a gran escala, elaborada con GPS de precisión y con trabajo de campo exhaustivo, que sea de consulta obligatoria ante cualquier actuación territorial en el litoral alicantino, el cual alberga una elevada biodiversidad de gran valor por contener especies raras y/o endémicas, y que sea la base para conectar las diferentes figuras de protección de manera realmente efectiva. Como ejemplo de la efectividad de poseer esta información, se exponen dos situaciones acaecidas en el litoral del municipio de Orihuela (Alicante) que afectaron a Helianthemum caput-felis Boiss. y a Tudorella mauretanica Pallary.

Quedarían pendientes otros problemas a solventar a la hora de constituir la Infraestructura Verde, no tratados en esta investigación, sobre todo en las zonas metropolitanas, como es la falta de conexión escalar entre una ordenación más de detalle de sus componentes y la que ofrecen los instrumentos de planificación metropolitanos (Feria Toribio \& Santiago Ramos, 2017, p. 137).

\subsection{Distribución general y estado de conservación actual de las especies Helianthemum caput-felis Boiss y Tudorella mauretanica Pallary}

En este trabajo, nos centramos en dos especies amenazadas por este desarrollo urbanístico, cuya área de distribución actual en la Comunitat Valenciana se ciñe al litoral alicantino: Helianthemum caput-felis Boiss. y Tudorella mauretanica Pallary. Para el caso de la primera, se localiza en sectores litorales de la península ibérica (litoral septentrional y meridional de la provincia de Alicante), Islas Baleares, Melilla (Figura 2), Cerdeña (Italia), Argelia y Marruecos. Pese a esta engañosa amplia distribución, las poblaciones españolas son cada vez más puntuales y fragmentadas, por lo que, si bien en un principio se catalogaba como "Vulnerable" (Padilla, 2002, pp. 122-124; Bañares ef al., 2004), recientemente se la considera como "En Peligro" (Moreno et al., 2008; Bañares et al., 2010; Aguilella et al., 2010; Agulló et al., 2013). De todos modos, en los catálogos no se ha homogeneizado su nueva categoría y, aunque en la Lista Roja de Flora Vascular Española (2008) sí que se considera "En peligro", en el Catálogo Español de Especies Amenazadas y en el Catálogo Valenciano de Especies de Flora Amenazadas todavía se le mantiene como "Vulnerable". 
Figura 2. Mapa de distribución de Helianthemum caput-felis Boiss. en España

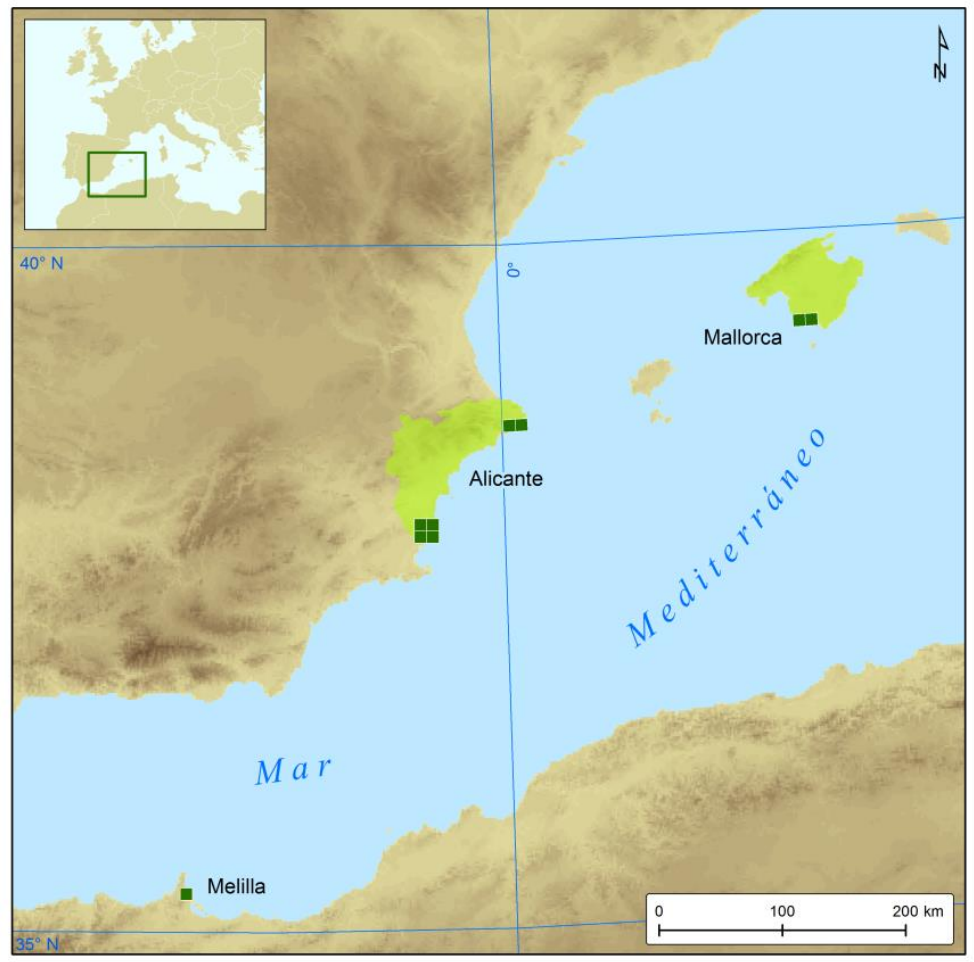

Fuente: elaboración propia a partir de Mateo \& Soler (1994), Domínguez et al. (1994),

Serra et al. (2000) y Servei de Vida Silvestre-Generalitat Valenciana (2016)

Su extinción es evidente en algunos sectores, como el de la población existente en Santa Pola (Domínguez et al., 1994), que se considera extinta desde hace unos años (Serra, 2000). El hábitat de esta planta se corresponde con matorrales secos litorales que colonizan substratos calcáreos y pedregosos, localizándose ejemplares tanto sobre la culminación plana de esos acantilados como en el talud; aunque también penetra hacia el interior (Marco et al., 2006), como es el caso de la Dehesa de Campoamor (Aguilella et al., 1994; Pujol, 2001), allí donde todavía quedan solares sin edificar ocupados por tomillares termófilos.

Aunque la administración pública ha realizado el seguimiento de estas poblaciones para conocer su dinámica en el transcurrir de los años, el uso de distintas metodologías de estimación de individuos ha devenido en una disparidad considerable en los resultados de las fuentes oficiales (BDBConselleria de Medi Ambient, Aigua, Urbanisme i Habitatge, Atlas y Libro Rojo de la Flora vascular amenazada de España y la Lista Roja de la UICN) no solo en el número de ejemplares, sino también en el Área de Ocupación (AOO) (Marco et al., 2016), información fundamental para determinar la categoría de amenaza de la UICN de cualquier especie. Este tipo de disparidades o carencias, incluso incoherencias, son desgraciadamente habituales y también han sido constatadas en otros trabajos de investigación (Gómez-Zotano et al., 2014). 
A nivel internacional, la jarilla cabeza de gato está incluida en el anexo I del Convenio de Berna (1979) y en el Anexo II y IV de la Directiva de Hábitats (92/43/CEE de 21 de mayo). En España está protegida por la Ley 42/2007, de 13 de diciembre, del Patrimonio Natural y de la Biodiversidad. En la Comunitat Valenciana, Helianthemum caput-felis Boiss. estaba incluida en el anexo I de la Orden de 20 de diciembre de 1985, de la Conselleria de Agricultura y Pesca (DOGV n³36) por la que se prohibía su recolección excepto con fines científicos, educativos o conservacionistas; hoy en día está derogada por la Ley 42/2007.

Actualmente, son cuatro los Lugares de Interés Comunitario (LIC) existentes en el ámbito de estudio: LIC Rambla de las Estacas, LIC Cabo Roig, LIC Litoral Cabo Roig y LIC Sierra Escalona y Dehesa de Campoamor (Figura 3). El primero de ellos, de apenas 0,20 ha, fue declarado en 1992, por la presencia de Helianthemum caput-felis Boiss, además de otras especies de interés. En el año 2014, este LIC fue revisado y corregido; tristemente, ya no se incluye en el listado a Helianthemum caputfelis, probablemente debido a su extinción.

Los otros dos LIC, espacio marino Cabo Roig y Litoral Cabo Roig son el resultado de la aplicación del acuerdo de la Generalitat Valenciana de 25 de abril de 2014 (DOGV N 7262 de 28.04.2014) por el que los espacios marinos protegidos pasan a ser de competencia estatal. En un principio, se declaró un espacio denominado como LIC Cabo Roig en 1992 que fue renombrado como LIC espacio marino Cabo Roig en 2014 (DOGV N 7262 de 28.04.2014/BOE, núm. 18, de 21 de enero de 2016). En realidad, desde su declaración toda la superficie protegida era marina (4686 ha.), salvo una hectárea terrestre que se correspondía con la propuesta de una microrreserva en Cabo Roig, que nunca se llegó a declarar como tal (Marco, 2005). A esta peculiaridad, se añade que los únicos ejemplares de jarilla cabeza de gato dentro del LIC se localizaban en la isla del Carmen en la Cala del Capitán, superficie no contabilizada como tierra emergida; por lo tanto, aunque uno de los objetivos del LIC declarado en 1992 era la protección del hábitat y de la especie de Helianthemum caput-felis Boiss., ésta nunca fue real (Marco, 2005). Hoy en día, esos pocos ejemplares han desaparecido debido a la formalización de un tómbolo a partir del año 2009 y la consiguiente conexión de esta isla con el continente. El acceso de las personas a este espacio y el pisoteo deben haber sido, sin duda, las causas de su desaparición. La aplicación del mencionado acuerdo de la Generalitat Valenciana de 2014 no ha supuesto modificación en la superficie marina que ocupaba el LIC de 1992; el único aspecto que ha variado es el referente a las especies prioritarias de protección, entre las que ya no se encuentra la jarilla cabeza de gato, debido a la no inclusión de las tierras emergidas. Con todo, en 2014 se crea el LIC Litoral de Cabo Roig, competencia de la Generalitat Valenciana, con una extensión de 7,15 ha. y en el que la única especie prioritaria es Helianthemum caput-felis Boiss.

Por último, al sur de la provincia de Alicante, pero no en la franja litoral analizada en esta investigación, se declaró en 1992 el LIC Sierra Escalona y Dehesa de Campoamor, con 4781,9 ha. 
La jarilla cabeza de gato también se incluye en la normativa de su declaración, junto a otras especies de flora y de fauna, debido a que su área de distribución penetra hacia el interior un par de kilómetros desde la costa.

Figura 3. Infraestructura verde. Espacios protegidos en el sur de la provincia de Alicante

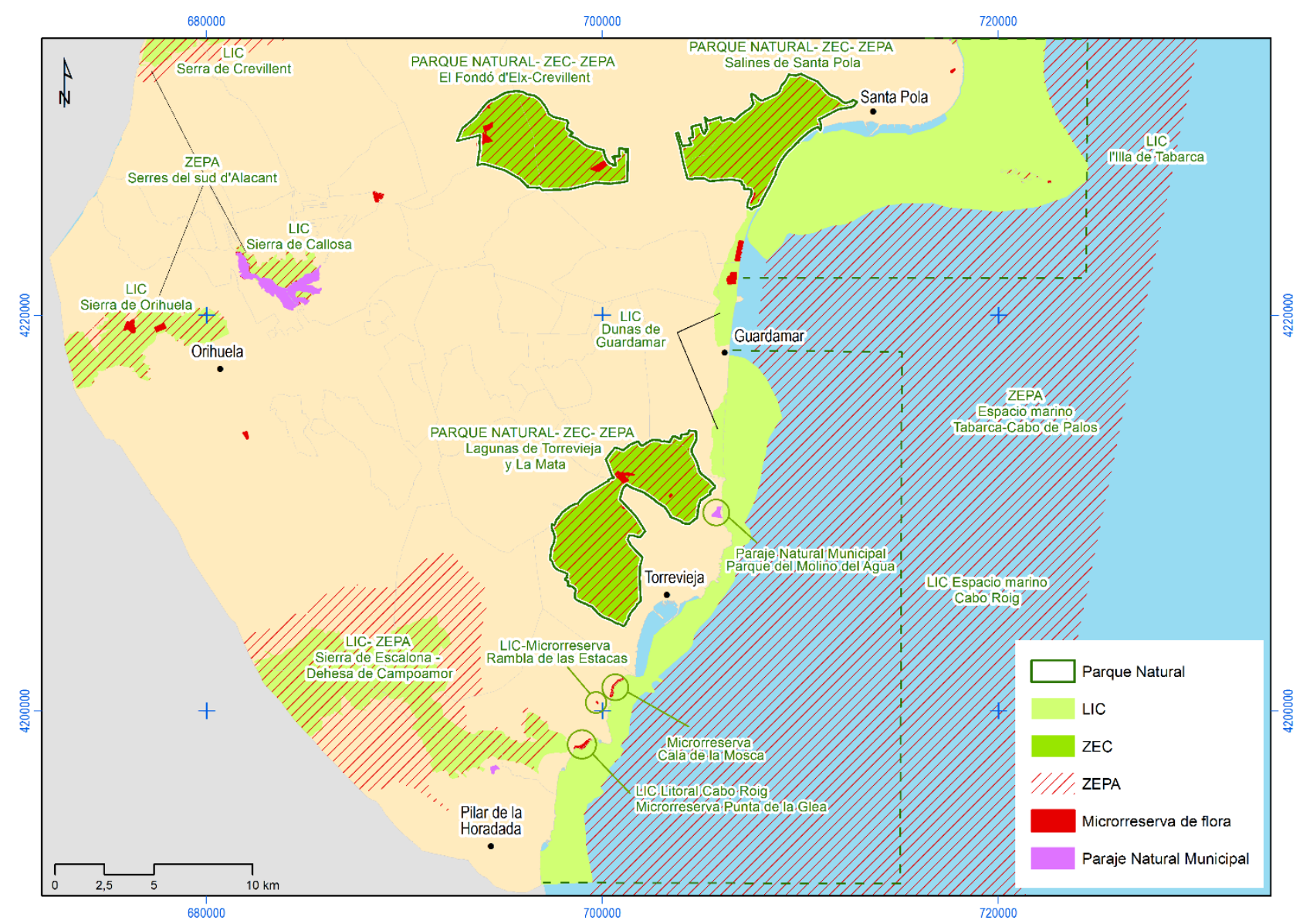

Fuente: elaboración propia a partir de (IDEV) Conselleria d'Infraestructures,

Territori i Medi Ambient, Generalitat Valenciana y Padilla et al. (2016)

En 1994, la Comunitat Valenciana fue pionera en la protección a nivel de especie, con la creación de las microrreservas vegetales (Decreto 218/1994), hoy denominadas microrreservas de flora. Tras aquel decreto, se propusieron un total de 50 para la provincia de Alicante, de las cuales cuatro incluían entre sus especies prioritarias a Helianthemum caput-felis Boiss.: Cabo Moraira, La Zenia, Dehesa de Campoamor y Cabo Roig (Padilla \& Ramón, 1997).

En la actualidad, las microrreservas de flora aprobadas en el sur de la provincia son (Generalitat Valenciana, visor web de cartografía temática): Rambla de las Estacas (1999), Punta de la Glea (2012) y Cala de la Mosca (2014) (Figura 3). La primera de ellas, muy probablemente, sea la microrreserva peor conservada y gestionada de toda la Comunitat Valenciana, debido al desarrollo urbanístico del municipio de Orihuela, que ha edificado hasta el límite mismo del área protegida, además del vertido de materiales de construcción y de escombros dentro de ésta. El grupo de 
investigación MedSPai realiza el seguimiento de esta población de jarilla cabeza de gato desde el año 2000 y ha podido constatar la total extinción de ejemplares por artificialización, ruderalización y nitrificación del hábitat.

La microrreserva de Punta de la Glea fue declarada en 2012, con una superficie de 6,92 ha. Dos años más tarde, coincidiendo prácticamente con esta área, se declaró el LIC Litoral de Cabo Roig. Se trata de uno de los espacios del litoral alicantino con las mejores poblaciones de jarilla cabeza de gato y en buen estado de conservación. Por otra parte, esta figura legal incluye otras especies prioritarias.

La tercera microrreserva es la de Cala de la Mosca, con una superficie de 2,95 ha y declarada en 2014. Helianthemum caput-felis es la única especie prioritaria de conservación recogida en el documento de declaración. Aunque en el siguiente apartado comentaremos este caso, merece la pena destacar aquí que la superficie protegida se ciñe al Dominio Público Marítimo Terrestre (DPMT).

Por todo lo expuesto hasta el momento y otros motivos que se indicarán más adelante, se pueden considerar a las microrreservas de flora como un parche, más que como una solución. Basta tener en cuenta que en el artículo 2 de la Orden de la Generalitat Valenciana por la que se declara esta figura legal de conservación se indica que si dentro del área de protección hay alguna infraestructura viaria, eléctrica o cualquier tipo de construcción preexistente, no se considera parte de la microrreserva, es decir, no le afecta el plan de gestión o normas de uso y limitaciones que se establezcan.

Respecto a la distribución de Tudorella mauretanica Pallary, es similar a la de jarilla cabeza de gato, en cuanto a su amplitud, fragmentación y pocos individuos en cada población. Se conoce en el NO de Argelia (Agulló et al, 2017), NE de Marruecos, SE de Francia, Córcega, Cerdeña, Sicilia, Malta y en el SE de España; es decir, Mediterráneo occidental. Se han encontrado restos en yacimientos pliocuaternarios del interior de la península ibérica, correspondiéndose con etapas de clima cálido (Robles \& Martínez-Ortí, 1995; Martínez-Ortí, 1999; Martínez-Ortí \& Robles, 2005); tras las glaciaciones, quedó reducida a posiciones próximas al mar.

En España, se localiza en Granada (Tajo de Escalante, Motril) y en Alicante (Paraje Natural Río Seco en Pilar de la Horadada, Rambla de la Estaca en Orihuela y cursos situados inmediatamente al norte y al sur de estos dos). Según la descripción de su hábitat en el Banco de datos de la Naturaleza del MAGRAMA, entre otras formaciones vegetales en las que aparece, se encuentra en los matorrales mediterráneos de la asociación Sideritido-Helianthemetum caput-felicis. Si observamos la distribución de Helianthemum caput-felis Boiss. y de Tudorella mauretanica Pallary en la provincia de Alicante, ambas coinciden en el sur, en el litoral de los municipios de Orihuela y 
Pilar de la Horadada, concretamente en la Cala de la Mosca y en la Rambla de las Estacas (Figura $4)$.

Figura 4. Área de distribución de Helianthemum caput-felis Boiss. y Tudorella mauretanica Pallary en la Comunitat Valenciana (CUTM $10 \mathrm{~km}^{2}$ )

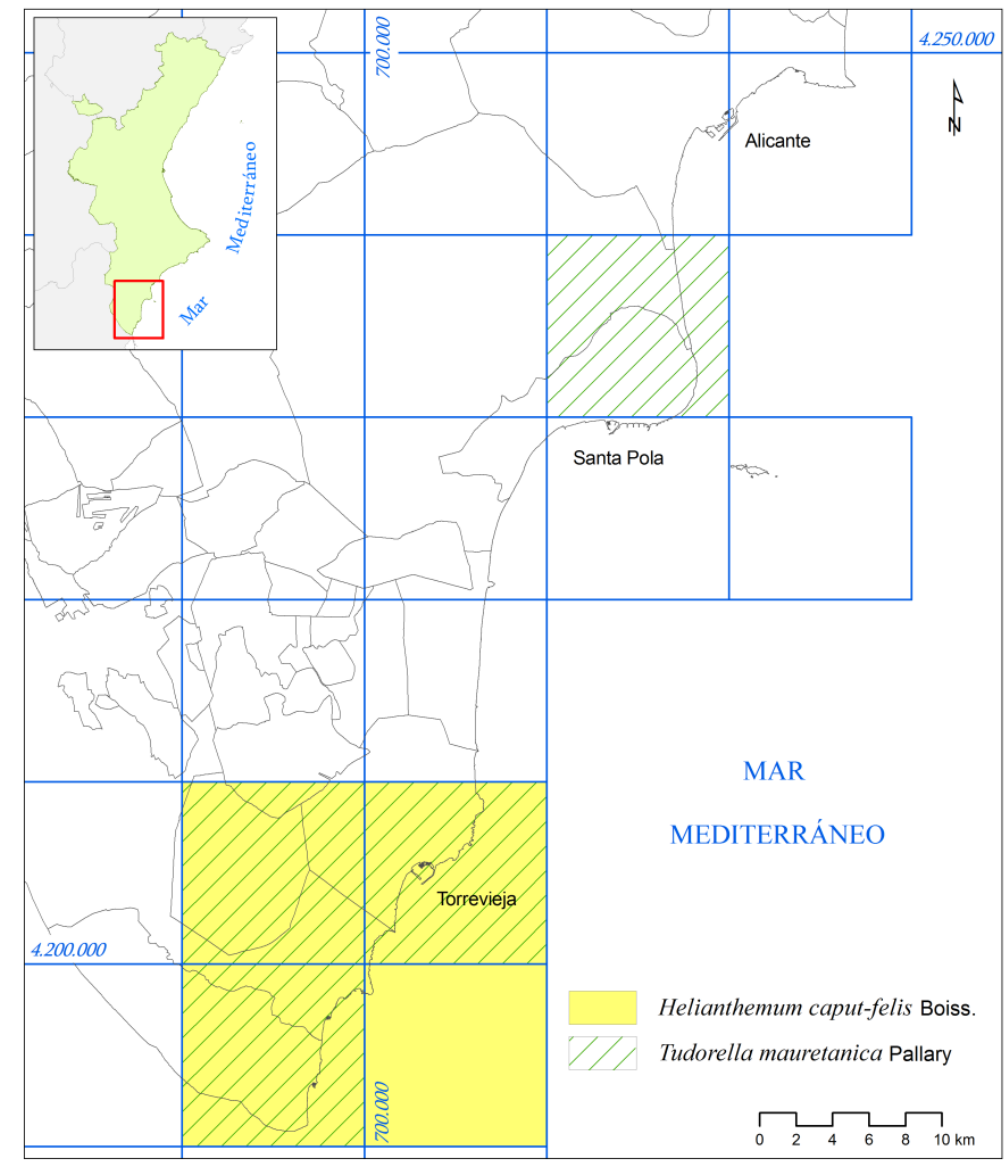

Fuente: elaboración propia a partir

de Infraestructura Valenciana de Datos Espaciales y Padilla et al. (2016)

Tudorella mauretanica Pallary es una especie catalogada como EN a nivel nacional (Verdú et al., 2011, p. 1225) y como "Vulnerable" en la Comunitat Valenciana. Su única protección legal es la de estar incluida en el Catálogo Valenciano de Especies de Fauna Amenazadas (Anexo I); curiosamente como Tudorella sulcata Draparnaud, especie que se localiza en un sector más oriental del Mediterráneo occidental. Ha sido encontrada también en la microrreserva vegetal de la Rambla de las Estacas, declarada en 1999, aunque no aparece en el documento legal de la declaración de esta figura, ni como especie prioritaria, ni en su plan de gestión.

Debido a la elevada amenaza de esta población por el desarrollo urbanístico, se traslocó a un monte de utilidad pública relativamente próximo, la Serra de Santa Pola; pero que, hasta hoy en día, no tiene ningún tipo de protección. El traslado de esta especie es una actuación cuestionable por la distancia entre las dos localidades y porque no hay datos de existencia de Tudorella 
mauretanica Pallary en dicho monte. Es preciso añadir que con fecha de 7 de octubre de 2016, el ayuntamiento de Santa Pola solicitó el inicio de los trabajos previos para la tramitación del Paraje Natural Municipal de la Serra y Cap de Santa Pola por parte de la Conselleria de Agricultura, Medio ambiente, Cambio climático y Desarrollo Local y que, en la actualidad, está en fase de exposición pública. En caso de que no exista ninguna alegación durante un período de 45 días, se publicará el decreto de declaración en el diario oficial de la Generalitat Valenciana.

Interesante también es el caso de la microrreserva de Cala la Mosca (2014) que al ceñirse su perímetro al DPMT, no incluye las poblaciones de Tudorella mauretanica Pallary, puesto que éstas se localizan más al interior, entre las masas de pinar.

Al estar incluido este taxon en el Catálogo Valenciano de Especies de Fauna Amenazadas, la Generalitat Valenciana está obligada a elaborar un Plan de Conservación de la especie; por el momento, no se ha redactado y, cuando se ejecute, el MAGRAMA aconseja que debería corregirse el error taxonómico antes mencionado. Dentro de las propuestas del Ministerio, se incluye también la declaración de una Reserva de Fauna Silvestre en el Monte de Utilidad Pública de la Serra de Santa Pola donde se traslocaron ejemplares de Tudorella mauretanica Pallary; reiterar la reubicación de aquellas poblaciones que están en grave peligro de extinción; ejecutar medidas y actuaciones de protección para las de Orihuela; realizar un seguimiento de la especie competidora Leonia mamillaris Lamarck (1822); incluir a Tudorella mauretanica Pallary en el Catálogo Nacional de Especies Amenazadas y en el Catálogo de Fauna Amenazada de Andalucía; así como, homogeneizar su categoría UICN a "En peligro de extinción" en todos estos documentos.

Las amenazas que acechan a Helianthemum caput-felis Boiss. y a Tudorella mauretanica Pallary, son prácticamente las mismas y giran fundamentalmente en torno al proceso urbanizador del litoral vinculado a la actividad turística-residencial, urbanización y trazado de infraestructuras, ordenación del frente litoral, introducción de especies autóctonas y alóctonas, acumulación de basuras y escombros, y un largo etcétera. (Marco et al., 2006, 2011, 2014; Padilla et al., 2014). En la Tabla 1 se exponen tanto estas amenazas antropogénicas, como las naturales, así como los efectos que producen en las poblaciones de Helianthemum caputfelis Boiss., y que pueden extrapolarse a Tudorella mauretanica Pallary, con excepción de las de origen natural.

Dos especies que son sólo la punta del iceberg de la situación actual de amenaza de la flora y fauna del litoral mediterráneo. Es urgente, por tanto, la elaboración y ejecución de planes de gestión y de conservación a diferentes escalas, pero fundamentalmente en la de detalle (Marco, 2012). Para ello, la disponibilidad de información sobre su localización precisa, así como el estado actual de conservación y la generación de una base de datos (Buades \& Marco, 2012) es clave 
para poder realizar su seguimiento diacrónico y, sobre todo, para elaborar una cartografía corológica de obligada consulta y previa a la intervención en el territorio.

Tabla 1. Amenazas sobre Helianthemum caput-felis Boiss. en el litoral sur de Alicante

\begin{tabular}{|c|c|}
\hline \multicolumn{2}{|c|}{ AMENAZAS ANTROPOGÉNICAS } \\
\hline PROCESOS & EFECTOS \\
\hline Urbanización & $\begin{array}{l}\text { Reducción-eliminación de la especie y } \\
\text { su hábitat } \\
\text { Artificialización del hábitat } \\
\text { Fragmentación de las poblaciones } \\
\text { Competencia vegetal con especies } \\
\text { exóticas }\end{array}$ \\
\hline $\begin{array}{l}\text { Ordenación frente litoral: } \\
\text { - } \quad \text { paseos marítimos } \\
\text { - ajardinamientos } \\
\text { - } \text { accesos a playas }\end{array}$ & $\begin{array}{l}\text { Reducción-eliminación de la especie y } \\
\text { su hábitat } \\
\text { Artificialización del hábitat } \\
\text { Fragmentación de las poblaciones } \\
\text { Competencia vegetal con especies } \\
\text { exóticas }\end{array}$ \\
\hline $\begin{array}{l}\text { Frecuentación (ocio/recreación): } \\
\text { - tránsito de vehículos } \\
\text { - estacionamiento } \\
\text { - } \quad \text { pisoteo de personas y } \\
\text { animales domésticos }\end{array}$ & $\begin{array}{l}\text { Degradación de la especie y su hábitat } \\
\text { Fragmentación de las poblaciones } \\
\text { Reducción-eliminación de la especie y } \\
\text { su hábitat }\end{array}$ \\
\hline Agricultura & $\begin{array}{l}\text { Reducción-eliminación de la especie y } \\
\text { su hábitat } \\
\text { Artificialización del hábitat } \\
\text { Fragmentación de las poblaciones }\end{array}$ \\
\hline \multicolumn{2}{|c|}{ AMENAZAS NATURALES } \\
\hline Dinámica geomorfológica & $\begin{array}{l}\text { Fragmentación de poblaciones } \\
\text { Fluctuaciones extremas } \\
\text { Reducción-eliminación de la especie y } \\
\text { su hábitat }\end{array}$ \\
\hline Dinámica vegetal & $\begin{array}{l}\text { Competencia con especies autóctonas } \\
\text { Fragmentación de poblaciones } \\
\text { Reducción-eliminación de la especie y } \\
\text { su hábitat }\end{array}$ \\
\hline Parasitismo & Mortalidad de ejemplares \\
\hline
\end{tabular}

Fuente: Marco et al. (2006, p. 11) 
Para evitar la desaparición de estas dos especies, así como de otras tantas, es fundamental la conectividad entre los hábitats de interés y de estas poblaciones fragmentadas, pero muchas veces prima la titularidad privada de esos terrenos y/o los intereses urbanísticos. La franja litoral en la que conviven Helianthemum caput-felis Boiss. y Tudorella mauretanica Pallary, aunque en hábitats diferentes, tiene una elevada importancia ecológica y medioambiental (Figuras 3 y 4), como es el caso de la zona húmeda de las lagunas de La Mata y Torrevieja (Catálogo de Zonas Húmedas de Importancia Internacional-RAMSAR, Catálogo de Zonas Húmedas valenciano, LIC, Zonas de Especial Conservación o ZEC y Zonas de Especial Protección de Aves o ZEPA, Parque Natural de la Comunitat Valenciana), Sierra de Escalona-Dehesa de Campoamor (LIC y ZEPA), Dunes de Guardamar (LIC), litoral Cabo Roig (LIC), espacio marino de Tabarca-Cabo de Palos (LIC), Parque del Molino de Agua (Paraje Natural Municipal) y Cala de la Mosca, Rambla de las Estacas y Punta de la Glea (Microrreservas de flora) (Marco, 2005).

La conexión entre todos estos espacios, ya protegidos, es la puesta en práctica de la gestión integrada del litoral que persigue el Consell de la Generalitat con la Infraestructura Verde Valenciana (2011/235 Decreto 1/2011, de 13 de enero, del Consell, por el que se aprueba la Estrategia Territorial de la Comunitat Valenciana) y con el futuro Plan de Acción Territorial de la Infraestructura Verde del Litoral (PATIVEL).

\section{Metodología}

Los resultados aportados en este trabajo son el fruto de varios años de investigación en los que ha tenido un gran peso el trabajo de campo y el uso de herramientas TIG. Por otra parte, para contextualizar la Infraestructura Verde en el litoral de la Comunitat Valenciana, se ha realizado una consulta exhaustiva de la documentación legal y de las publicaciones existentes hasta la actualidad, relacionadas con dicha temática. Del mismo modo, se han visitado los enlaces de organismos públicos con el fin de argumentar el estado de protección y de exponer la información oficial sobre el área de distribución, las amenazas y las actuaciones de mejora y conservación de las dos especies objeto de este estudio, Helianthemum caput-felis Boiss. y Tudorella mauretanica Pallary: Unión Internacional para la Conservación de la Naturaleza (UICN), Ministerio para la Transición Ecológica y Conselleria de Agricultura, Medio Ambiente, Cambio Climático y Desarrollo Rural de la Comunitat Valenciana.

El grupo de investigación MedSPai de la Universidad de Alicante y autor de esta investigación ha realizado campañas de seguimiento de la poblaciones de Helianthemum caput-felis Boiss. desde el año 2000 (Giménez et al., 2008; Marco et al., 2006, 2007, 2008, 2011, 2012, 2014, 2016; Padilla et al., 2014) con toma de datos de ejemplares y conjuntos de ejemplares mediante recolectores GPS de precisión submétrica y corrección en postproceso (serie Geo XH de Trimble), lo que ha permitido elaborar una cartografía corológica con cuadrículas UTM de 1x1 km, acorde 
con la existente en el Banco de Datos de la Biodiversidad de la Generalitat Valenciana. En los últimos dos años, se ha colaborado con personal técnico de VAERSA para actualizar y revisar los datos existentes y completar las bases de datos de la Consellería. Las capas de información obtenidas en las prospecciones de campo se han cruzado mediante el software QGIS con otras de planeamiento y usos del suelo, pudiendo conocer con mayor exactitud la dinámica y área de distribución de esta especie.

Por otra parte, desde el año 2010 se han realizado diversos inventarios de Tudorella mauretanica Pallary en varias parcelas clasificadas como suelo urbano en el vigente Plan General de Ordenación Urbana de Orihuela, en el entorno de las ramblas de las Estacas y de la cala de la Mosca, fragmentadas en numerosos puntos tanto por las urbanizaciones como por las infraestructuras de transporte. En ambos casos, mediante el censo directo, se buscaba la determinación de la presencia de la especie y la densidad de sus poblaciones aisladas en estos reductos de maquia mediterránea densificada con pinares de repoblación.

En resumen, con toda la información recopilada, se ha elaborado una cartografía corológica de las dos especies analizadas en esta investigación y de las figuras de protección existentes, ciñéndonos al litoral sur alicantino. A escala de detalle, en los dos casos expuestos del municipio oriolano, se ha realizado un análisis espacial al cruzar o solapar las capas de información de la distribución de las subpoblaciones y ejemplares de Helianthemum caput-felis Boiss con el ordenamiento de la parcela "Alameda del Mar" del PGOU de Orihuela y la Infraestructura Verde; además de la representación cartográfica de las actuaciones de restauración del hábitat de Tudorella mauretanica Pallary. La parte gráfica de esta investigación tiene un gran peso dentro de la metodología propuesta, ya que constituye la base de la documentación o inventario ambiental necesario para la protección efectiva de la biodiversidad y la configuración definitiva de la Infraestructura Verde del litoral sur de la Comunitat Valenciana.

\section{Resultados}

La finalidad de esta investigación ha sido elaborar una cartografía básica de consulta ante la ejecución de cualquier proyecto de urbanización del litoral alicantino para evitar la extinción de estas especies o, en el mejor de los casos, la fragmentación de sus poblaciones. En este trabajo se presentan dos ejemplos localizados en el sector litoral del municipio de Orihuela (Alicante). El resultado fue la declaración de la microrreserva Cala la Mosca en 2014, en la que se incluyen ambas especies, y la redistribución de la edificabilidad del proyecto para el sector UE-2 del PGOU.

En la definición del vigente Plan General de Ordenación Urbana del municipio de Orihuela, aprobado en 1990, no se tuvieron en cuenta las cuestiones de carácter ambiental y paisajístico del Decreto 120/2006, de 11 de agosto, del Consell y de la Ley 12/2009, de 23 de diciembre, 
mencionadas en la introducción de este artículo, sino que se atendió preferentemente a la promoción de los usos residenciales y turísticos en el litoral, ignorando la existencia de espacios naturales de relevancia, de hábitats de interés comunitario y de especies de flora y fauna protegidas legalmente.

El 11 de noviembre del 2015, la Conselleria d'Habitatge, Obres Públiques i Vertebració del Territori emitió una resolución por la que se iniciaba el Plan de Acción Territorial de la Infraestructura Verde del Litoral de la Comunitat Valenciana, PATIVEL (DOCV 7658, 16 de noviembre de 2015), y que finalmente se aprobó en mayo del pasado año (DECRETO 58/2018, de 4 de mayo, del Consell, por el que se aprueba el Plan de Acción Territorial de la Infraestructura Verde del Litoral de la Comunitat Valenciana y el Catálogo de Playas de la Comunitat Valenciana).

En la revisión del Plan General oriolano se atienden los requerimientos de la actual legislación valenciana en materia de ordenación del territorio, urbanismo y paisaje, por lo que se define la Infraestructura Verde municipal, incorporando los espacios de Red Natura 2000, así como las áreas protegidas por instrumentos internacionales como es el hábitat que comparten Helianthemum caputfelis Boiss. y Tudorella mauretanica Pallary en las ramblas y cañadas litorales del sur de la Comunitat Valenciana. En los casos trabajados, se trata de suelos clasificados como urbanos o urbanizables por el vigente planeamiento municipal (aunque en diferente estado de tramitación), como sucede en las unidades de ejecución residenciales de los planes parciales de "Alameda del Mar" (UE-1, en el frente litoral al norte de la Cala de la Mosca) y del Sector E-2 "El Barranco" (UE2, parcelas ZB1 y ZB2). En las dos localizaciones se ha propuesto sendas modificaciones puntuales con el fin de preservar el hábitat compartido por las dos especies, reordenando las parcelas edificables, a la vez que se han desarrollado diferentes acciones de conservación.

\subsection{Helianthemum caput-felis Boiss.: integración de cartografía corológica detallada en el diseño de planes urbanísticos.}

Motivado por la constatación de pérdida de ejemplares durante las campañas de prospección, en gran parte debida al rápido desarrollo urbanístico, se decidió elaborar una cartografía corológica de detalle a partir del año 2006. Con ello, también se ha observado la reducción del área de ocupación y se han verificado las amenazas existentes. Los resultados han permitido determinar la disparidad de datos en las fuentes oficiales: Banco de Datos de la Biodiversidad (Conselleria de Agricultura, Medio Ambiente, Cambio Climático y Desarrollo Rural), Atlas y Libro Rojo de la Flora vascular amenazada de España (Ministerio para la Transición Ecológica) y la Lista Roja de la UICN.

La información presentada ha permitido elaborar una cartografía corológica con cuadrículas UTM de 1x1 km, acorde con la existente en el Banco de Datos de la Biodiversidad de la Generalitat Valenciana. La información presentada se corresponde con la actualización y la revisión de los 
datos existentes en las campañas realizadas hasta mayo de 2017 en colaboración con personal técnico de VAERSA (Figura 5).

En el año 2007, se inició la ejecución del proyecto de urbanización de la parcela urbana UE-2 del sector D-1, "la Alameda del Mar", localizado al norte de la Cala de la Mosca (Orihuela) y que establecía la edificación de 1500 viviendas. Esta parcela, clasificada como Suelo Urbano según el PGOU (1990), constituye, aún hoy en día, la única zona sin urbanizar del litoral oriolano y de las pocas de toda la provincia de Alicante. En aquellas fechas, el SEPRONA paralizó las obras, al observar la extinción de ejemplares de Helianthemum caput-felis Boiss. y la degradación de su hábitat. La empresa urbanizadora contrató a la consultora "Cota Ambiental, S.L" y al grupo de investigación MedSPai para que realizaran una propuesta de reparcelación y de medidas con el fin de conservar la especie vegetal y una valoración de los daños ocasionados por el proceso urbanizador. Para la redacción de dicho informe fue fundamental la información corológica obtenida en las campañas del año 2006, lo que permitió calcular el área de ocupación estricta de jarilla cabeza de gato, estimada en 3,15 ha, y realizar el perímetro de las áreas que se había roturado, obtenido con GPS de precisión. Con el análisis espacial de estas dos capas de información, se obtuvo la zona afectada, unas 0,58 ha (Giménez et al., 2008). Era esencial conocer las áreas de conflicto, es decir, aquellas en las que la ejecución del proyecto urbanizador supondría la eliminación total de poblaciones de Helianthemum caputfelis Boiss.; por lo que también se cruzó la cartografía corológica con el planeamiento de la urbanización. Las medidas que se propusieron buscaban la máxima protección y conservación de la especie vegetal, como de su hábitat. En el año 2012, la Conselleria d'Infraestructures, Territori i Medi Ambient resolvió la realización de un estudio de evaluación de impacto ambiental de la parcela "Alameda del Mar". Como consecuencia, la empresa urbanizadora solicitó una actualización de la cartografía corológica de la planta con el fin de realizar un nuevo diseño del plan parcial en el que se tuvieran en cuenta las afecciones y la distribución de Helianthemum caput-felis Boiss.

De la comparativa entre los censos de 2006 y 2012-2013, se observó que en algunas zonas que habían sido removidas para la apertura de viales, la especie había funcionado como pionera en la colonización vegetal. Por lo tanto, si bien en el 2007 se eliminaron poblaciones con esta intervención, desde esa fecha hasta el 2014 se regeneraron algunas manchas (Padilla et al., 2014). 
Figura 5. Cartografía corológica de Helianthemum caput-felis Boiss.

en el sur de Alicante (CUTM $1 \mathrm{~km}^{2}$ )

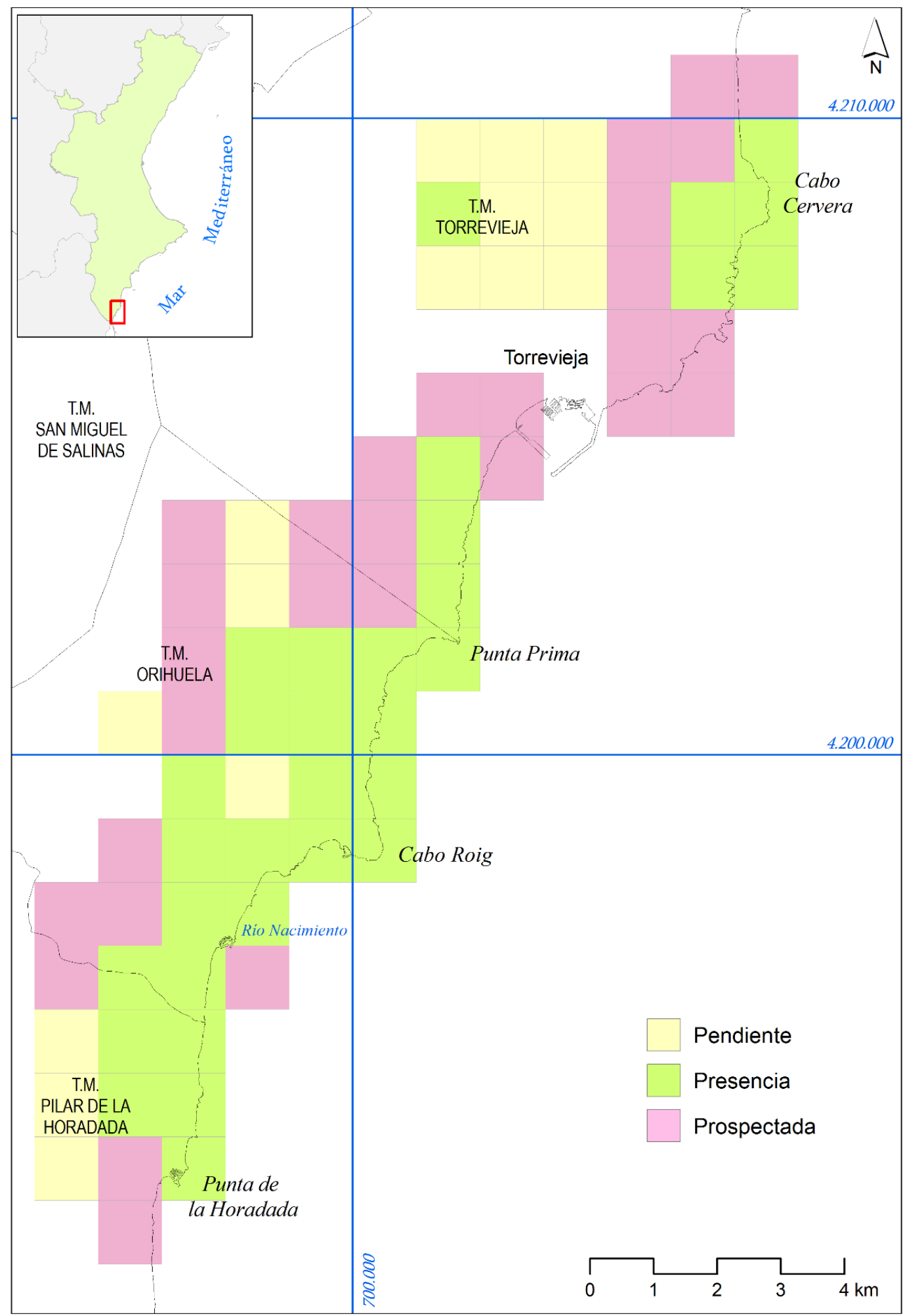

Fuente: elaboración propia a partir de MedSPai

\& VAERSA-Conselleria d'Infraestructures, Territori i Medi Ambient, Generalitat Valenciana 
Una de las medidas propuestas en el informe por MedSPai fue la creación de una microrreserva en la Cala la Mosca. La promotora estuvo de acuerdo y consideró la posibilidad de proponer su declaración a la Conselleria de Agricultura, Medio Ambiente, Cambio climático y Desarrollo Rural; pero la respuesta fue negativa debido a la imposibilidad de la declaración de esta figura legal en suelo urbano. Por este motivo, se declaró una microrreserva vegetal en suelo de dominio público, fuera del sector D-1, abarcando todo el frente litoral de la parcela "Alameda del Mar", es decir, el DMPT, obviando las poblaciones existentes dentro de la parcela urbana UE-2. La aplicación de la ley, sin admitir excepciones, ha supuesto que el sector de mayor número de ejemplares no quede protegido de la actuación urbanística. Además, se ha estimado que aproximadamente un 74,22 \% de plantas no se han incluido en esta figura de protección (Tabla 2); porcentaje a todas luces insuficiente porque se protegen los ejemplares correspondientes a un solo hábitat, dejando al margen los que hay en la parte superior del acantilado o en los pinares donde también está presente Tudorella mauretanica Pallary (Figura 6).

Finalmente, la modificación del proyecto de urbanización de la parcela UE-2 consistió en calificar como dotacional (equipamiento público educativo ambiental) y como espacios libres-zonas verdes (parques y jardines y áreas de juego) el área donde se localizaron una mayor densidad de ejemplares de Helianthemum caput-felis Boiss., es decir, el sur y el frente litoral de la parcela UE-2 (Figura 7); fruto de la aplicación del Código de urbanismo de la Comunitat Valenciana (Capítulo II, art. 77 , b.) por el que el aprovechamiento por compensación de excedentes que corresponde a la administración es del $15 \%$, destinado a la mejora de la infraestructura verde.

Del análisis espacial realizado, que ha consistido en solapar las capas de información de la distribución (puntos y polígonos) de jarilla cabeza de gato, de la microrreserva vegetal de Cala la Mosca y de la calificación del suelo de la parcela UE-2 (Figura 6), se puede afirmar que 5357 ejemplares (34,38 \%) desaparecerán si se ejecuta este plan de ordenación, que se corresponden con los localizados en "turístico residencial", "aparcamiento - viario", "terciario - equipamiento playa", "peatonal - vía pecuaria" y "áreas de juego" (Tabla 2). Para las zonas denominadas como "parques y jardines" y "equipamiento público de educación ambiental" se presupone que se respetarán una serie de normas que no perjudiquen a esta especie vegetal, como es la plantación de vegetación autóctona característica de estos hábitats, la no introducción de especies exóticas y/o invasoras, la prohibición del pisoteo o apertura de sendas por los viandantes, la conservación de las características del suelo y/o formación superficial, entre otras; con estas condiciones, podríamos considerar que el $39.84 \%$ de los ejemplares se podrían conservar. En el caso de que se obvien este tipo de consideraciones, esos 6207 ejemplares se sumarían a la cantidad anterior de taxones eliminados. Lo que sí se puede asegurar es que, al menos, un 25,78\% tienen asegurada la viabilidad, siempre y cuando las afecciones de las zonas limítrofes a la microrreserva vegetal de Cala la Mosca no repercutan negativamente y supongan un impacto a estas 
subpoblaciones de Helianthemum caput-felis Boiss., como se ha podido observar en la de la Rambla de las Estacas (Marco al., 2011).

Figura 6. Microrreserva vegetal de Cala la Mosca, subpoblaciones de Helianthemum caput-felis Boiss. y propuesta de reparcelación en el sector UE-2 del PGOU de Orihuela (líneas de color rojo)

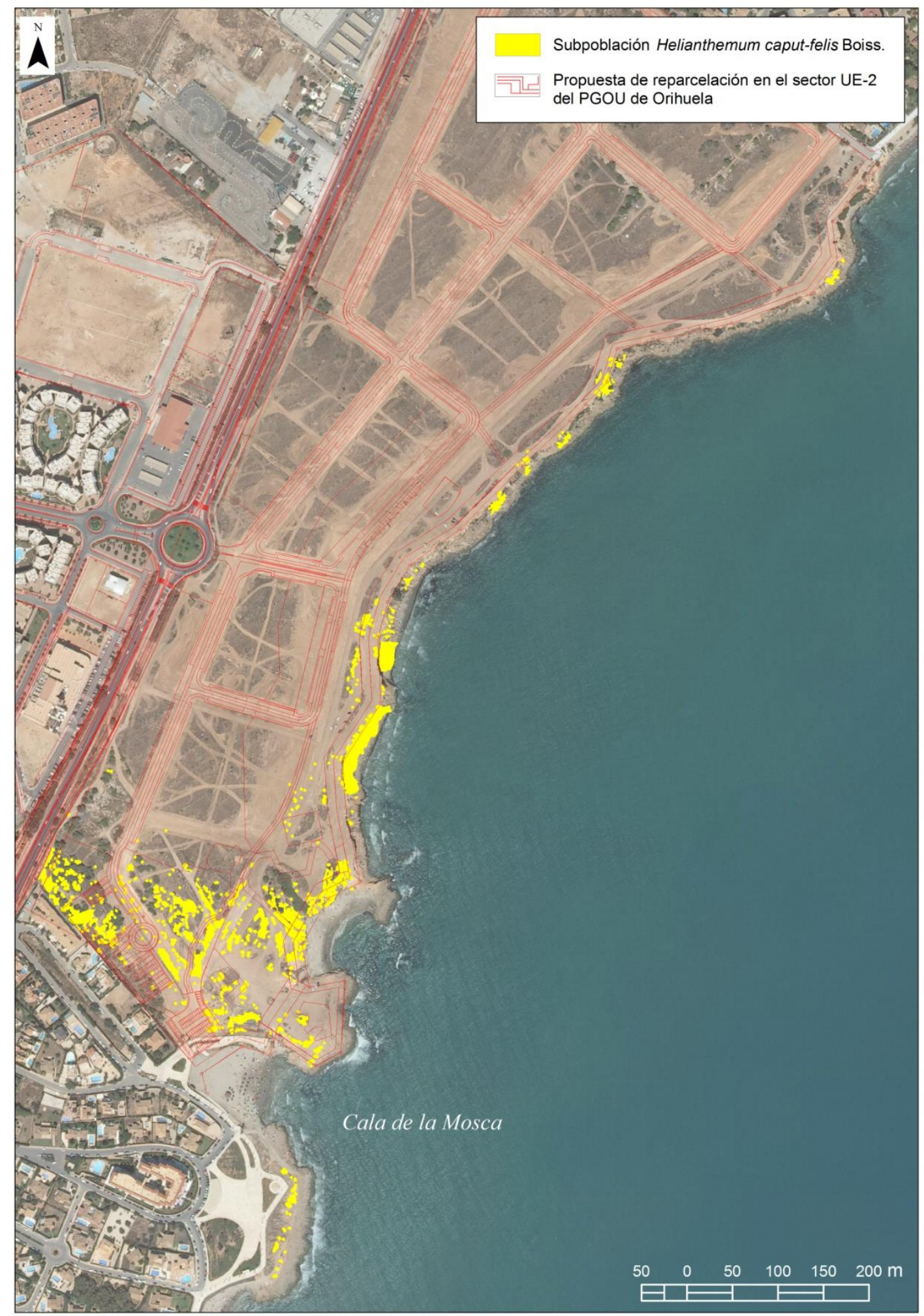

Fuente: elaboración propia a partir de Padilla et al. (2016) 


\section{Figura 7. Ordenamiento de la parcela "Alameda del Mar" (PGOU de Orihuela)}

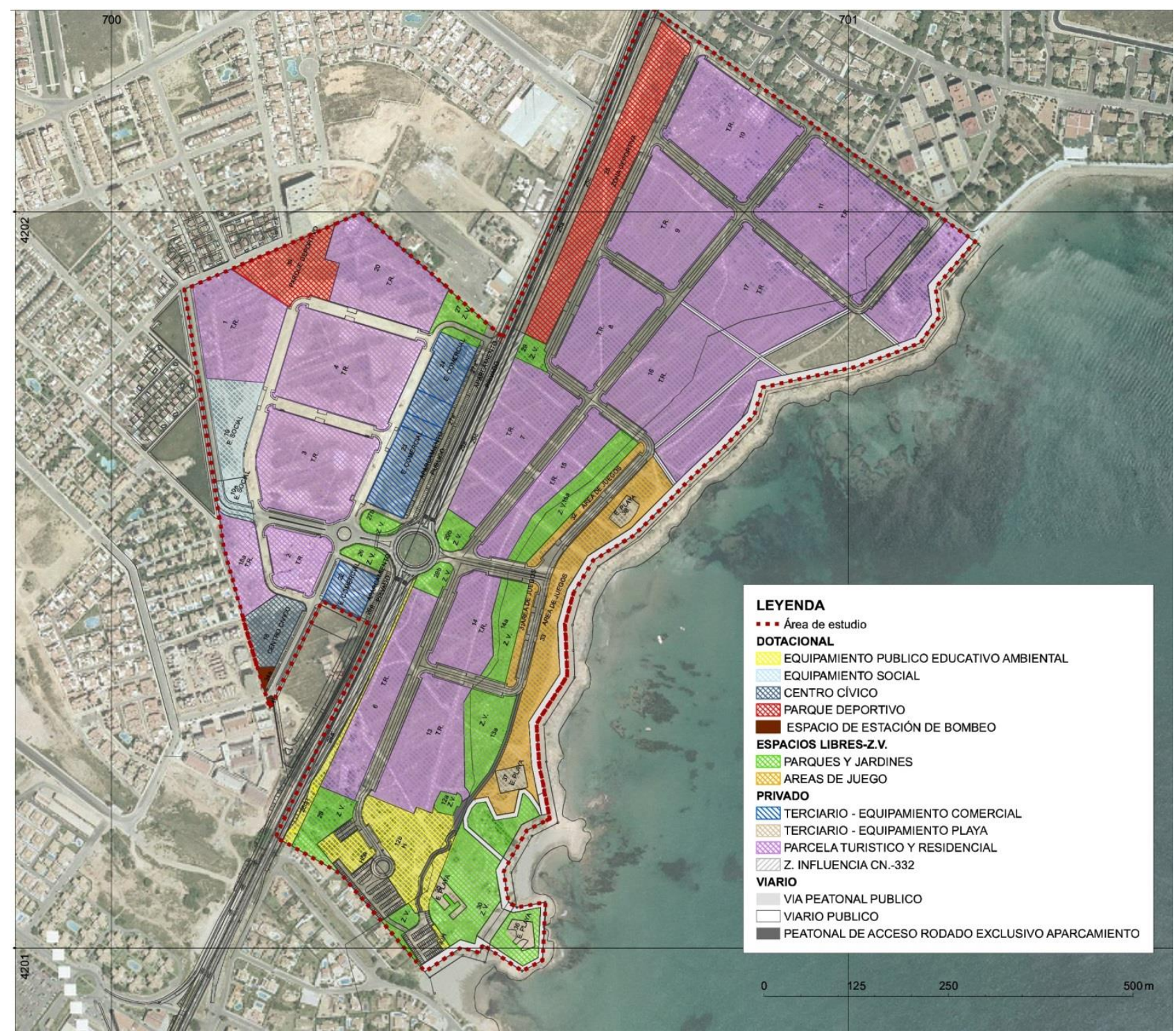

Fuente: López (2013)

El proceso de exposición pública de la modificación del proyecto de urbanización de la parcela UE2 del sector D-1 "Alameda del Mar" fue en julio del 2014. El ayuntamiento de Orihuela tardó casi dos años en publicar la información y envió los documentos a la Conselleria d'Habitatge, Obres Públiques i Vertebració del Territori a principios de 2017. Por lo tanto, el informe todavía está en tramitación a fecha de publicación del presente trabajo.

En la primera versión del PATIVEL (2016), la parcela aparece dentro de las categorías de suelos urbanos y urbanizables; sin embargo, en la segunda versión (2017), el sector meridional de la UE2, donde hay un mayor número de individuos y poblaciones de Helianthemum caput-felis Boiss., aparece parcialmente clasificada como "suelos transitorios", que se regulan a través de la normativa del plan "Disposición transitoria única. Ámbitos con programa de actuación aprobado" (Generalitat Valenciana, 2016). 
Tabla 2. Número de ejemplares de Helianthemum caput-felis Boiss. afectados por el ordenamiento de la parcela "Alameda del Mar" (PGOU de Orihuela)

\begin{tabular}{|l|l|l|l|l|}
\hline CALIFICACIÓN DEL SUELO & $\begin{array}{l}\text { NÚMERO DE } \\
\text { EJEMPLARES } \\
\text { AISLADOS }\end{array}$ & $\begin{array}{l}\text { NÚMERO DE } \\
\text { EJEMPLARES } \\
\text { EN } \\
\text { MANCHAS }\end{array}$ & $\begin{array}{c}\text { NÚMERO } \\
\text { TOTAL DE } \\
\text { EJEMPLARES }\end{array}$ & $\begin{array}{c}\text { PORCENTAJE } \\
(\%)\end{array}$ \\
\hline TURÍSTICO-RESIDENCIAL & 5 & 0 & 5 & 0.03 \\
\hline APARCAMIENTO-VIARIO & 118 & 248 & 366 & 2.35 \\
\hline TERCIARIO EQUIP. PLAYA & 23 & 0 & 23 & 0.15 \\
\hline PEATONAL-VÍA PECUARIA & 310 & 4531 & 4841 & 31.07 \\
\hline ÁREAS DE JUEGO & 122 & 0 & 122 & 0.78 \\
\hline PARQUES Y JARDINES & 401 & 3331 & 3732 & 23.95 \\
\hline EQ. PÚB. ED. AMBIENTAL & 308 & 2168 & 2475 & 15.89 \\
\hline MICRORRESERVA & 32 & 3986 & 4018 & 25.78 \\
\hline TOTAL & 1319 & 14264 & 15583 & 100 \\
\hline
\end{tabular}

Fuente: elaboración propia

Precisamente, ésta es la situación de la UE-2 del sector D1 "Alameda del Mar", que cuenta con programa de actuación aprobado pero cuyo procedimiento de evaluación ambiental del proyecto de urbanización se encuentra en tramitación desde el año 2012, tras la movilización social por la protección de las poblaciones de jarilla cabeza de gato existentes en la zona meridional del suelo urbano.

En la versión aprobada definitivamente del PATIVEL mediante el Decreto 58/2018 (DOGV núm. $8293,11 / 05 / 2018$ ) se incluye el sector de Orihuela-Cala Mosca en la ficha 50 de la Memoria Informativa, con una superficie de 13,43 ha como Suelo No Urbanizable de Protección Litoral, especificando su singularidad dentro de la categoría de "suelos transitorios". Así, en la Disposición Transitoria Primera del mencionado Decreto 58/2018, referida a los ámbitos con programa de actuación aprobado, se determina que estos:

deberán ejecutar y finalizar las obras de urbanización en los plazos y condiciones establecidos en la legislación vigente en el momento de la aprobación del programa. En ningún caso, el inicio de las obras de urbanización podrá superar los cinco años desde la aprobación del presente plan y la finalización y recepción de las obras de urbanización y dotaciones públicas cinco años más.

Si transcurridos esos períodos no se hubieran cumplido dichas obligaciones, estos suelos sí quedarán sujetos a lo dispuesto en el PATIVEL, por lo que el agente urbanizador de la UE-2 del 
Sector D1 "Alameda del Mar" tiene hasta mayo de 2023 para iniciar las obras de urbanización y hasta mayo de 2028 para finalizarlas.

En este sentido, la modificación del proyecto de urbanización de la UE-2 del Sector D-1 "Alameda del Mar", promovido por Playa Salvaje, S.A., cuenta con Declaración de Impacto Ambiental de fecha 9 de mayo de 2018 que lo estima aceptable, desde el punto de vista ambiental y sin perjuicio de la previa obtención de las autorizaciones sectoriales que le sean de aplicación, con una serie de condicionantes que incorporan, entre otras, medidas para la protección y gestión de los hábitats tanto de Helianthemum caput-felis Boiss como de Tudorella mauretanica Pallary, mediante la delimitación de sendas reservas de flora y fauna, reguladas mediante el Decreto 70/2009, de 22 de mayo, del Consell y el Decreto 32/2004, de 27 de febrero, del Consell, respectivamente. Ambas reservas quedan integradas en la Infraestructura Verde municipal del litoral oriolano.

\subsection{Tudorella mauretanica Pallary: acciones de restauración del hábitat.}

En febrero de 2014, el Pleno municipal del Ayuntamiento de Orihuela aprobó la modificación puntual al Plan Parcial del sector E-2 "El Barranco" del Plan General Municipal de Ordenación Urbana, promovida por la mercantil Moorstyle España, S.L., consistente en el trasvase de edificabilidad entre las manzanas ZB-1 y ZB-2, integradas en la unidad de ejecución n². Esta modificación puntual fue consecuencia de la detección de la existencia de ejemplares de Tudorella mauretanica Pallary en las zonas colindantes con el cauce de la Rambla de las Estacas, pertenecientes a dicha unidad de ejecución $n^{\circ} 2$. De esta forma, se procedió a delimitar y proteger el hábitat de la especie en este tramo, a raíz de un informe de la empresa Gesta, S.L. que sirvió de base para la redacción de un posterior plan de seguimiento ambiental. Los datos de campo reflejaban la existencia de tres zonas de localización de la especie con una superficie total de unos $4500 \mathrm{~m}^{2}$, con densidades muy altas distribuidas en cincuenta colonias con una estimación de diez ejemplares en cada una de ellas. Las principales amenazas determinadas fueron la degradación del hábitat por presión humana y la muerte por ingesta por parte de rata común (Rattus norvegicus) y rata negra (Rattus rattus).

Con posterioridad, en marzo de 2016, durante el período de ejecución de las obras de urbanización y construcción de la unidad de ejecución $n^{\circ} 2$, se acometió la realización de actuaciones de restauración del hábitat de Tudorella mauretanica Pallary en dicho tramo de la rambla de las Estacas. Las acciones de restauración ambiental sobre una superficie de más de $11000 \mathrm{~m}^{2}$ (Figura 8) consistieron en:

- Limpieza de la zona, con retirada de escombros y basuras, realizada a mano, cubriendo con abundante pinocha los ejemplares de Tudorella mauretanica Pallary detectados, con el fin de evitar su deshidratación. Asimismo, se procedió a la tala y retirada de los ejemplares de especies invasoras tales como ricinos (Ricinus communis) y mimosas (Acacia dealbata). 
- Poda y retirada de ejemplares de pino carrasco (Pinus halepensis), tras la identificación junto a los agentes medioambientales de aquellos secos o que pudieran causar riesgos de incendios forestales por su localización en el entorno de las construcciones.

- Restauración del sustrato edáfico, utilizando uno con características similares al original y existente en los alrededores, pues la mayoría de especies de moluscos son muy sensibles a los cambios en el sustrato.

- Plantación de especies vegetales autóctonas (arbóreas y arbustivas) como el pino carrasco (Pinus halepensis), lentisco (Pistacia lentiscus), el palmito (Chamaerops humilis), el espino negro (Rhamnus lycioides), el esparto (Stipa tenacissima) y el albardín (Lygeum spartum). Una vez acondicionado el terreno se ha procedido a la plantación manual al tresbolillo y, puntualmente, en rodales, manteniendo un marco de plantación medio de unos 2,0-2,0 m de separación entre plantones. La superficie de actuación de la plantación ha comprendido el camino y la explanada central de la margen derecha del cauce de la rambla de las Estacas, así como una franja al pie del muro de hormigón generado por la urbanización. Los ejemplares de las especies arbustivas, con portes de 1-2 savias, se localizaron en un área de $2900 \mathrm{~m}^{2}$ con una densidad de $1500 \mathrm{ud} / \mathrm{ha}$, con abundante riego inicial y sucesivos riegos mensuales de socorro entre los meses de mayo y septiembre de 2016.

Entre 2014 y 2019 se ha ejecutado el sector E-2 "El Barranco" con la construcción de ocho edificios en los que se acumula toda la edificabilidad permitida en el plan parcial aprobado y modificado, para salvaguardar el hábitat de Tudorella mauretanica en lo que queda de la cuenca alta de la rambla de las Estacas, donde se han ejecutado las medidas de recuperación expuestas. Por tanto, los datos obtenidos por el seguimiento científico han permitido modificar la calificación de las localizaciones de Tudorella mauretanica Pallary, destinándolas a zonas verdes y espacios libres (sin urbanización ni ajardinamiento), a la vez que se ha transferido la edificabilidad de ambas parcelas a otras de las mismas unidades de ejecución.

Se trata, pues, de un claro ejemplo de concreción de la Infraestructura Verde a nivel local en la microescala de un sector de planeamiento de desarrollo del Plan General Municipal de Ordenación Urbana de Orihuela. La protección legal de la especie y la necesaria conservación de su hábitat ha conllevado la modificación de una figura de planeamiento aprobada definitivamente mediante una modificación puntual fundamentada en criterios ambientales integrando casi el 50 \% de la superficie del sector E2 en la Infraestructura Verde local. 
Figura 8. Actuaciones de restauración del hábitat de Tudorella mauretanica Pallary (Rambla de las Estacas, Orihuela)

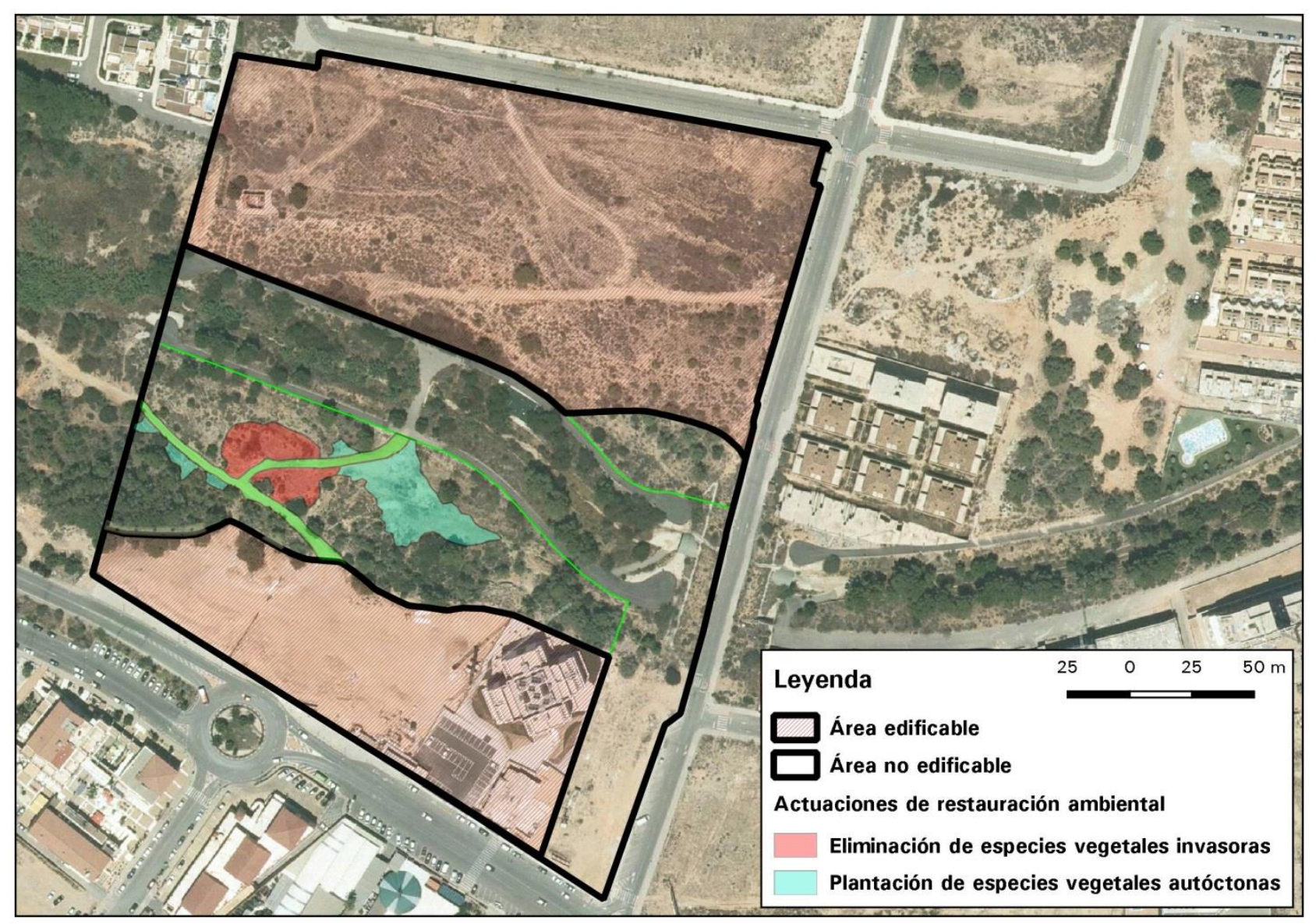

Fuente: elaboración propia a partir de Generalitat Valenciana y Cota ambiental S.L.P. (2016)

\section{Discusión de resultados}

El interés por la conservación de la biodiversidad, de hábitats prioritarios y de flora rara, endémica o amenazada, es evidente en la legislación europea, nacional (Ley 42/2007) y autonómica (Ley 11/1994) a través de medidas de conservación in situ y ex situ, creación de corredores ecológicos y un largo etcétera que forman parte de la política de gestión del patrimonio natural. Sin embargo, para alcanzar este fin, es necesario partir de una información detallada referente a la distribución, abundancia, estado actual, usos, dinámicas de cada especie y hábitat; es decir, la elaboración de un inventario ambiental exhaustivo que sea de obligada consulta ante la planificación o ejecución de cualquier actuación territorial.

La información existente es cada vez más amplia y completa, pero presenta carencias y hay disparidades entre los organismos públicos en muchas ocasiones, como se ha manifestado en esta investigación para el caso de la catalogación del riesgo de amenaza o denominación científica de Tudorella mauretanica Pallary que es diferente en la documentación nacional o autonómica. Otra 
de las carencias detectadas ha sido la diversidad en las metodologías usadas para el seguimiento de las poblaciones de Helianthemum caput-felis Boiss que redundan en un resultado diferente de la aplicación de los criterios de la UICN y, a su vez, puede repercutir en una menor rigurosidad de las medidas de protección y conservación que se tomen, puesto que se enmascara la realidad: ubicación puntual y poblaciones poco numerosas.

La distribución espacial de las figuras de protección en el litoral alicantino reflejan el importante desarrollo urbanístico y la ocupación de ese territorio por este uso y por las infraestructuras viarias y de comunicación. De este modo, la conectividad entre hábitats de interés y de las poblaciones, fragmentadas por estas causas, es bastante utópica. Con las microrreservas de flora se intenta favorecer la conexión ecológica a escala de detalle pero, en realidad, son pequeños "parches" de protección que, para el caso de Helianthemum caput-felis Boiss en el litoral sur alicantino, apenas superan superficies de 7 ha. Este pequeño tamaño es debido a las razones ya expuestas en este párrafo.

En resumen, la efectividad y posibilidad de crear una Infraestructura Verde en el litoral sur de la Comunitat Valenciana es bastante compleja e, incluso, irreal sino se refuerzan las debilidades mencionadas, además de tener en cuenta la necesidad de gestionar el territorio a diversas escalas de manera coherente e interrelacionada. Nos pueden servir de ejemplo otros casos a nivel internacional de conservación de los hábitats naturales y, por ende, de protección de especies, mediante la regulación de los procesos de planificación urbana, como son: el Biotope Area Factor (BAF) en Berlín (Alemania), el Space Green Factor en Malmo (Suecia), el Seattle Green Factor en Seattle (EE.UU.) o el Greening Sydney Plan en Sydney (Australia). De estos ejemplos, el BAF berlinés (Berlin Stadportal) incide en mayor medida en la normativa urbanística y en la planificación de las zonas verdes desde un enfoque de conectividad ecológica, estableciendo directrices para la mejora del entorno residencial mediante la protección de los biotopos y hábitats vegetales y animales.

En este trabajo se pone de manifiesto cómo la disponibilidad de una cartografía corológica detallada y precisa favorece a la conservación y protección de dos especies amenazadas: Helianthemum caput-felis Boiss.y Tudorella mauretanica Pallary. Así, en ambos casos, las reservas de flora y fauna delimitadas en los hábitats de ambas especies quedan integradas en la Infraestructura Verde local del litoral del municipio de Orihuela, de la que forman parte, a diferentes escalas (Figura 9 y Figura 10), tanto el espacio Red Natura 2000 del LIC de Cabo Roig, como los terrenos deslindados como Dominio Público Marítimo Terrestre, la vía pecuaria de la Cañada Real de la Costa, las calas y playas determinadas en el Plan de Acción Territorial de la Infraestructura Verde del Litoral (PATIVEL) y los espacios abiertos propios de ambos sectores (zonas verdes y jardines). 
Figura 9. Infraestructura Verde local del litoral del municipio de Orihuela

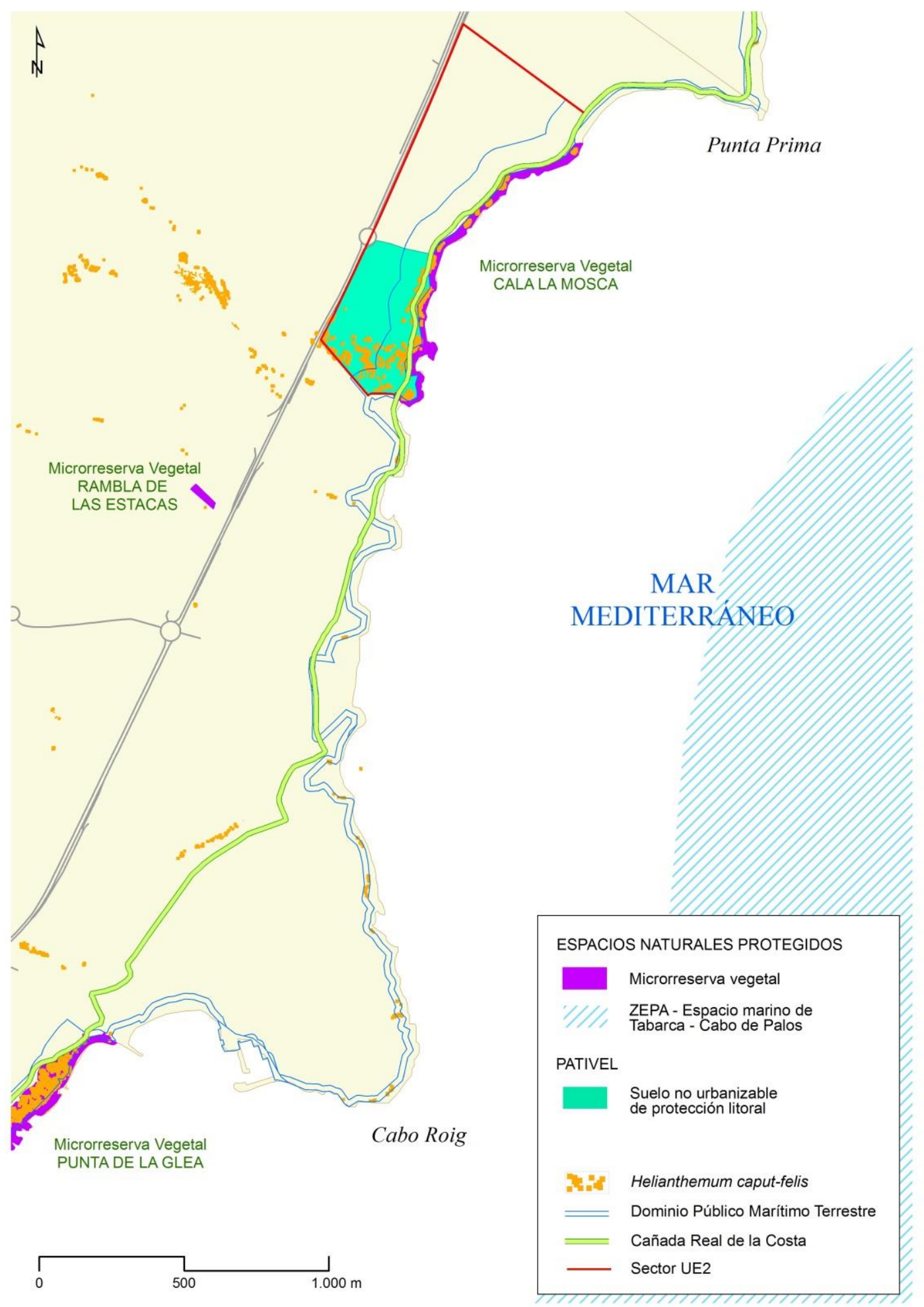

Fuente: elaboración propia a partir de Generalitat Valenciana y Cota ambiental S.L.P. (2019) 
Figura 10. Infraestructura Verde local de la parcela UE-2 del Sector D1 "Alameda del Mar"del litoral del municipio de Orihuela

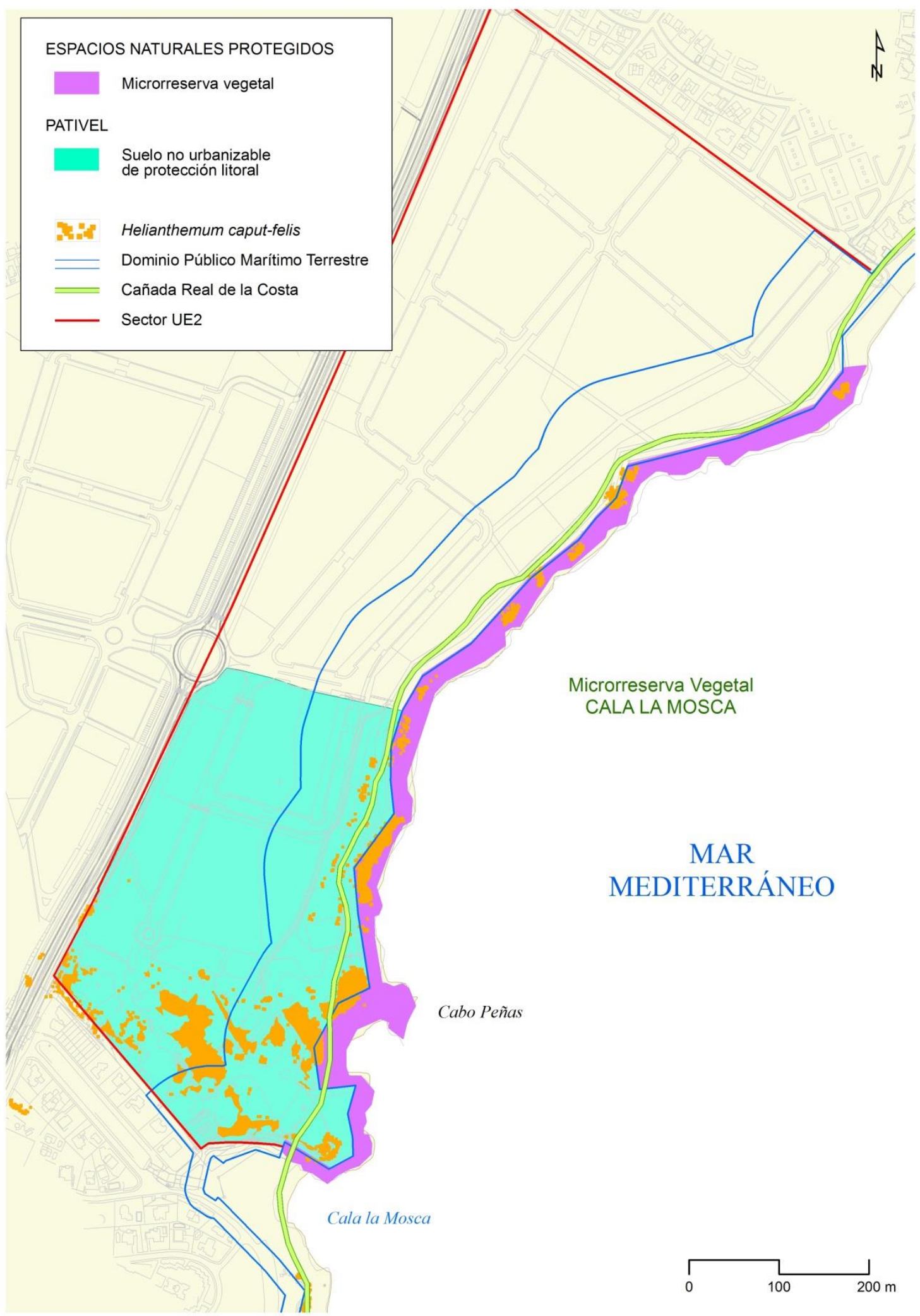

Fuente: elaboración propia a partir de Generalitat Valenciana y Cota ambiental S.L.P. (2019) 
Las dinámicas observadas y analizadas en detalle de las especies Helianthemum caput-felis Boiss.y Tudorella mauretanica Pallary no constituyen un caso único y aislado del litoral sur alicantino y, mucho menos, del resto de la provincia. Si nos ceñimos al área de estudio, son bastantes los taxones que se encuentran en esta situación de amenaza de extinción debido a la expansión urbanística y al planeamiento vigente. Solo teniendo en cuenta aquellas especies consideradas por la UICN con un mayor peligro, podemos listar las aves Aquila fasciata (En Peligro-UICN) y Aythya nyroca (En Peligro Crítico-UICN); el coleóptero Paratriodonta alicantina (En Peligro-UICN); los peces Aphanius iberus (En Peligro-UICN) y Valencia hispanica (En Peligro-UICN) y la planta Helianthemum marminorense (En Peligro-UICN). Todas ellas requieren estudios detallados y de seguimiento, así como la elaboración de cartografía corológica y bases de datos ambientales que permitan su protección y conservación de manera efectiva. Solo así se podrá constituir una Infraestructura Verde real.

Declaración responsable: Las/os autoras/es declaran que no existe ningún conflicto de interés en relación con la publicación de este artículo. Las tareas se han distribuido de la siguiente manera: Ascensión Padilla redacción de la introducción, estado y conservación de Helianthemum caputfelis Boiss.; Antonio Prieto Cerdán redacción del contenido referente a Infraestructura Verde y Tudorella mauretanica Pallary; Juan Antonio Marco Molina y Pablo Giménez Font redacción de la distribución, corología y amenazas de Helianthemum caput-felis Boiss.; y Angel Sánchez Pardo corrección y gestión de datos GPS, elaboración cartográfica y SIG. Todas/os las/os autoras/es han participado en la recolección de datos con GPS y en la redacción de la metodología, resultados y discusión de resultados. 


\section{Bibliografía}

Agencia Territorial de la Unión Europea 2020 (2011). Hacia una sociedad integradora, inteligente y sostenible para una Europa de Regiones diversas. Hungary. Retrieved from https://ec.europa.eu/regional_policy/sources/policy/what/territorialcohesion/territorial_agenda_2020.pdf

Agència Valenciana del Turisme (2018). El turismo en la Comunitat Valenciana 2017, Valencia: Generalitat Valenciana. Retrieved from

http://www.turisme.gva.es/tcv/tcv2017/2_Alicante_2017c.pdf

Aguilella, A., Fos, S., \& Laguna, E. (Eds.) (2010). Catálogo Valenciano de Especies de Flora Amenazadas. Valencia: Conselleria de Medi Ambient, Aigua, Urbanisme i Habitatge, Generalitat Valenciana.

Agulló, J.C., Juan, A., Alonso, M.A., \& Crespo, M.B. (2013). Helianthemum caput-felis. The IUCN Red List of Threatened Species 2013 (e.T162013A5530070). Retrieved from https://www.iucnredlist.org/species/162013/5530070

Agulló, J.C., Juan, A., Crespo, M.B., Alonso, M.A., \& Terrones, A. (2017). An updated report on the distribution and conservation status of the endangered Cat's Head Rockrose Helianthemum caputfelis (Magnoliopsida: Violales: Cistaceae) in Algeria. Journal of Threatened Taxa, 9(3), 9885-9891. http://dx.doi.org/10.11609/jott.2592.9.3.9885-9891

Banco de Datos de la Biodiversidad (2019). Generalitat Valenciana. Retrieved from http://www.bdb.gva.es/es/

Banco de Datos de la Naturaleza. MAGRAMA: Retrieved from www.magrama.gob.es/es/biodiversidad/servicios/banco-datos-naturaleza/

Bañares, Á., Blanca, G., Güemes, J., Moreno, J.C. \& Ortiz, S., (eds.) (2004). Atlas y Libro Rojo de la Flora Vascular Amenazada de España. Madrid, Dirección General de Conservación de la Naturaleza.

Bañares, A., Blanca, G., Güemes, J., Moreno, J.C., \& Ortiz, S. (Eds.) (2010). Atlas y Libro Rojo de la Flora Vascular Amenazada de España. Adenda 2010. Dirección General de Medio Natural y Política Forestal (Ministerio de Medio Ambiente, y Medio Rural y Marino \& Sociedad Española de Biología de la Conservación de Plantas.

Buades, J., \& Marco, J.A. (2012). Integración de bases de datos espaciales para el registro de datos corológicos de táxones vegetales. In R. Cunill, A. Pèlachs, R. Pérez-Obiol \& J.M. Soriano, (Eds.), Las zonas de montaña: gestión y biodiversidad (pp. 226-232). Barcelona: Fundació Catalunya-Caixa, Mont Natura Pirineus. 
BERLIN STADTPORTAL (2019). Senate Departament for environment, transport and climate protection. Retrieved from

https://www.berlin.de/senuvk/umwelt/landschaftsplanung/bff/index_en.shtml

Cantó, $M^{a}$ T. (2014). La planificación y gestión de la Infraestructura Verde en la Comunitat Valenciana, Revista Aragonesa de Administración Pública, 43-44, 215-234. Retrieved from http://rua.ua.es/dspace/handle/10045/52822.

Capdepón Frías, M. (2016). Conflictos ambientales derivados de la urbanización turísticoresidencial. Un caso aplicado al litoral alicantino. Boletín de la Asociación de Geógrafos Españoles 71, 31-57, https://doi.org/10.21138/bage.2273

Domínguez D., Herbada, G., Moreno, L., Moreno, J.C., \& Sáinz, H. (1994). Asientos para un atlas corológico de la flora occidental, 22: Mapa 627 (adiciones). Fontqueria, 40, 143-144.

Feria Toribio, J.M., \& Santiago Ramos, J. (2017). Naturaleza y ciudad. Perspectivas para la ordenación de la Infraestructura Verde en los planes territoriales metropolitanos en España. Boletín de la Asociación de Geógrafos Españoles, 74, 117-141. https://doi.org/10.21138/bage.2447 Gaja, F. (2008). El "tsunami urbanizador" en el litoral mediterráneo. El ciclo de hiperproducción inmobiliaria 1996-2006, Scripta Nova, 270. Retrieved from www.ub.edu/geocrit/sn/sn-270/sn270-66.htm\#_edn1

Generalitat Valenciana (2019). Visor web de cartografía temática. Retrieved from http://cartoweb.cma.gva.es/visor/

Generalitat Valenciana (2017). PAT Infraestructura Verda del Litoral de la Comunitat Valenciana: Normativa. Retrieved from

http://www.habitatge.gva.es/documents/20551069/164304902/Normativa/fda9c20e-8b6e489d-aOfd-9097d99cdce3

Giménez, P., Sánchez, A., Padilla A., \& Marco, J.A. (2008). Integración de una cartografía corológica a escala de detalle mediante GPS en el proceso urbanizador: Helianthemum caput-felis Boiss. en el litoral sur de Alicante (España). In A. Galve \& V.M. Rodríguez (Eds.), Coloquio Ibérico de Geografía: la perspectiva geográfica ante los retos de la sociedad y el medioambiente en el contexto ibérico (DVD-4 ${ }^{a}$ ponencia, pp. 1-15). Alcalá de Henares. http://dx.doi.org/10.13140/RG.2.1.1951.0885

Gómez-Zotano, J., Román-Requena, F., Hidalgo-Triana, N., \& Pérez-Latorre, A.V. (2014). Biodiversidad y valores de conservación de los ecosistemas serpentínicos en España: Sierra Bermeja (provincia de Málaga). Boletín de la Asociación de Geógrafos Españoles, 65, 187-206. http://dx.doi.org/10.21138/bage. 1749 
Instituto Nacional de Estadística (INE) (2019). Demografía y población (INEbase). Retrieved from http://www.ine.es/dyngs/INEbase/es/operacion.htm?c=Estadistica_C\&cid=1254736176951\&m enu=ultiDatos\&idp $=1254735572981$

Infraestructura Valenciana de Datos Espaciales (IDEV). Generalitat Valenciana. Retrieved from http://www.idev.gva.es/es

López, J. (2013). Estudio de afecciones a la Red Natura 2000 de la modificación del proyecto de urbanización de la UE-2 del sector D-1 "Alameda del Mar" del PGOU de Orihuela (Alicante). Ayuntamiento de Orihuela (Unpublished).

MAGRAMA (2011). Evaluación de los ecosistemas del milenio de España. Conservación de los servicios de los ecosistemas y la biodiversidad para el bienestar humano. Informe final. Madrid: Ministerio de Medio Ambiente y Medio Rural y Marino. Retrieved from http://www.ecomilenio.es/wp-content/uploads/2012/03/00-Portada-preliminares-eintroducci\%C3\%B3n.pdf

Marco, J.A. (2005). Los humedales costeros del sur de Alicante: perspectiva evolutiva. In J.F. Vera (Coord.), Jornadas del Bicentenario. Torrevieja 1803-2003 (pp. 33-54). Ayuntamiento de Torrevieja-Universidad de Alicante.

Marco, J.A. (2012). Bases para la gestión del patrimonio natural. In L. Rubio \& G. Ponce (Eds.), Gestión del patrimonio arquitectónico, cultural y medioambiental. Enfoques y casos prácticos (pp. 95-114). Universidad Autónoma Metropolitana (México)-Universidad de Alicante.

Marco, J.A., Padilla, A., Sánchez, A., \& Giménez, P. (2006). Helianthemum caput-felis Boiss. entre Punta Prima y Cabo Roig (Litoral suralicantino). In P. Giménez, J. A. Marco, E. Matarredona, A. Padilla \& A. Sánchez (Eds.), Geografía Física y Medio Ambiente (pp. 169-182). Alicante: Asociación de Geógrafos Españoles. http://dx.doi.org/10.13140/RG.2.1.1164.6568

Marco, J.A., Padilla, A., Sánchez, A., \& Giménez, P. (2007). Consecuencias ambientales del proceso urbanizador en el litoral sur de Alicante el declive de Helianthemum caput-felis Boiss. In FUNDICOT V Congreso Internacional de Ordenación del Territorio, Área Temática Territorio (pp. 667-676). Málaga. http://dx.doi.org/10.13140/RG.2.1.3197.1682

Marco, J.A., Giménez, P., Padilla, A., \& Sánchez, A. (2008). Aplicaciones de las tecnologías SIG y GPS en la dinámica de poblaciones de flora amenazada: Helianthemum caput-felis Boiss. In L. Hernández \& J.M. Parreño (Eds.), Tecnologías de la Información Geográfica para el Desarrollo Territorial (pp. 635-649). Las Palmas de Gran Canaria: Servicio de Publicaciones y Difusión Científica de la ULPGC. http://dx.doi.org/10.13140/RG.2.1.1147.2480 
Marco, J.A., Giménez, P., Padilla, A., \& Sánchez, A. (2011). Crecimiento urbano y conservación de flora amenazada: aplicaciones cartográficas en el caso de Helianthemum caput-felis Boiss. Serie Geográfica, 17, 125-139.

Marco, J.A., Padilla, A., Sánchez, A., \& Giménez, P. (2012). Ensayo metodológico para la estimación de la pérdida de hábitat de Helianthemum caput-felis Boiss. en la Península Ibérica (1956-2005). In R. Cunill, A. Pèlachs, R. Pérez-Obiol \& J.M. Soriano (Eds.), Las zonas de montaña: gestión y biodiversidad (pp. 233-237). Barcelona: Fundació Catalunya-Caixa, Mont Natura Pirineus. http://dx.doi.org/10.13140/RG.2.1.4948.3360

Marco, J.A., Sánchez, A., Padilla, A., \& Giménez, P. (2014). Identificación de impactos sobre flora rara, endémica o amenazada mediante el análisis de secuencias espacio-temporales. In Tecnologías de la información para nuevas formas de ver el territorio: XVI Congreso Nacional de Tecnologías de Información Geográfica (pp. 516-526). Alicante: Asociación de Geógrafos Españoles.

Marco, J.A., Giménez, P., Padilla, A., \& Sánchez, A. (2016). Cartografía corológica y área de ocupación de Helianthemum caputfelis Boiss. en la Península Ibérica. In J. Gómez, J. Arias, J.A. Olmedo \& J.L. Serrano (Eds.), Avances en Biogeografía. Áreas de distribución: entre puentes y barreras (pp. 108-116). Granada: EGU-Tundra.

Martí, P., \& Nolasco, A. (2011). La expansión urbanística reciente de la costa alicantina, una realidad constatable, In V. Gonzálvez \& J.A Marco (Coords.), Geografía y desafíos territoriales en el siglo XXI. Urbanismo expansivo: de la utopía a la realidad (pp. 367-378). Alicante: Universidad de Alicante,

Martinez-Ortí, A. (1999). Moluscos terrestres testáceos de la Comunitat Valenciana (Doctoral dissertation, Universitat de Valencia, Spain). Retrieved from https://mvhn.files.wordpress.com/2012/10/martc3adnez-ortc3ad-a-1999.pdf

Martinez-Ortí, A., \& Robles, F. (2005). Los caenogasterópodos terrestres (Mollusca, Orthogastropoda) de la Comunitat Valenciana (España). Iberus, 23(2), 7-24.

Mateo, G., \& Soler, X. (1994). Asientos para un atlas corológico de la flora occidental, 22: Mapa 627. Fontqueria, 40, 142-143.

Mateo Sanz, G., \& Crespo, M.B (2003). Manual para la determinación de la flora valenciana (3ª edición). Alicante-Valencia: Monografías de Flora Montiberica.

Myers, N.; Mittermeier R.A.; Mittermeier, C.G., Da Fonseca, G. and Kent, J. (2000). Biodiversity Hotspots for Conservation Priorities. Nature, 403, 853-858.

http://dx.doi.org/10.1038/35002501 
Padilla, A. (2002). Protección y conservación de la flora en la Comunidad Valenciana. Investigaciones Geográficas, 27, 107-130. https://doi.org/10.14198/INGEO2002.27.09

Padilla, A., \& Such, M‥P. (2001). Biodiversidad florística y turismo en el litoral valenciano. In Actas del XVII Congreso de Geógrafos Españoles (pp. 188-194) Oviedo: Asociación de Geógrafos Españoles.

Padilla, A., \& Such, Ma.P. (2016). Incidencia de la modificación de la legislación de costas en la protección del litoral alicantino. In F. Vera, J. Olcina \& $M^{a}$ Hernández (Eds.), Paisaje, cultura y territorial y vivencia de la Geografía. Libro homenaje al profesor Alfredo Morales Gil (pp. 9731003). Alicante: Publicaciones Universidad de Alicante. https://doi.org/10.14198/LibroHomenajeAlfredoMorales2016-44

Padilla, A., Giménez P., Marco, J.A., \& Sánchez, A. (2014). Metodología sobre dinámica de poblaciones de Helianthemum caputfelis Boiss. a partir del análisis comparativo de los censos de 2006 y 2013 (litoral sur de Alicante, España. In R. Cámara \& B. Rodríguez (Eds.), Biogeografía de Sistemas Litorales. Dinámica y conservación (pp. 51-58). Sevilla: Vicerrectorado de Investigación de la Universidad de Sevilla-AGE. https://doi.org/10.13140/RG.2.1.2213.2322

Padilla, A., Prieto, A., Giménez, P., Sánchez, A., \& Marco, J.A. (2016). Aplicación práctica de la delimitación de la Infraestructura Verde en el litoral alicantino: Helianthemum caput-felis Boiss y Tudorella mauretanica Pallary. In Conama 2016. Retrieved from http://www.conama2016.org/

Prieto, F., (2009). Cambios en la ocupación del suelo en la costa 1987-2005: pérdida acelerada de servicios de los ecosistemas y destrucción de un bien común (Unpublished report).

Pujol, J.A. (2001). La urbanización de la costa alicantina marca el declive de la Jarilla de Cabeza de Gato. Quercus, 188, 43-46.

Robles, F., \& Martínez-Ortí, A. (1995). On the distribution of Pomatias sulcatus (Draparnaud, 1805) (Prosobranchia: Pomatiasidae), recent and fossil, in the Iberian Peninsula. In R. Guerra \& Rocha (Eds.), Abstract 12th International Malacological Congress (pp. 248-249). Vigo.

Serra, Ll., Fabregat, C., Herrero-Borgoñón, J.J., \& Udias, S. (2000). Distribución de la flora vascular endémica, rara o amenazada en la Comunitat Valenciana. Valencia: Generalitat Valenciana.

Servei de Vida Silvestre \& Direcció General de Medi Natural i d'Avaluació Ambiental (2016). La Jarilla Cabeza de Gato (Helianthemum caputfelis). Conservación, Amenazas y Estado Actual de Conocimiento en la Comunitat Valenciana. Valencia: Conselleria Agricultura, Medio Ambiente, Cambio climático \& Desarrollo Rural, Generalitat Valenciana. Retrieved from http://www.agroambient.gva.es/documents/91061501/162536532/IT15_2016+Jarilla+cabeza+ 
de+gato_Conservaci\%C3\%B3n_amenazas_estado+actual/9c19ee43-79a7-4192-822a-

$19461 f \mathrm{ff} 8 \mathrm{~b} 31$

Such, M.P. (1995). Turismo y medio ambiente en el litoral alicantino. Alicante: Instituto de Estudios Juan Gil-Albert.

Vera, J.F., Díez, D., \& Ivars-Baidal, J. (2009). El turismo interior en la Comunitat Valenciana: la percepción desde las entidades municipales y asociaciones turísticas. Serie Geográfica, 15, 2738, Retrieved from

https://ebuah.uah.es/dspace/bitstream/handle/10017/13903/27_38_turismo_Vera_SG_2009 N15.pdf? sequence=1\&isAllowed $=$ y

Vera F., \& Baños C. (2010). Renovación y reestructuración de los destinos turísticos consolidados del litoral: las prácticas recreativas en la evolución del espacio turístico. Boletín de la Asociación de Geógrafos Españoles, 53, 329-353. Retrieved from https://www.agegeografia.es/ojs/index.php/bage/article/view/1204

Verdú, J.R., \& E., Galante (Eds.) (2006). Libro Rojo de los Invertebrados de España. Madrid: Dirección General para la Biodiversidad \& Ministerio de Medio Ambiente.

Verdú, J.R., Numa, C., \& Galante, E. (eds) (2011). Atlas y Libro Rojo de los Invertebrados amenazados de España (EspeciesVulnerables). Madrid: Dirección General de Medio Natural y Política Forestal \& Ministerio de Medio Ambiente, Medio rural y Marino. Retrieved from:https://www. miteco.gob.es/es/biodiversidad/temas/inventarios-

nacionales/atlas_moluscos_vulnerables_tcm30-198388.pdf

\section{Legislación y normativa}

Acuerdo de 25 de abril de 2014, del Consell, por el que se adecuan los espacios protegidos de la Red Natura 2000 marinos y marítimo-terrestres al reparto de competencias en el medio marino establecido en la Ley 42/2007, de 13 de diciembre, del Patrimonio Natural y de la Biodiversidad. Diario Oficial de la Generalitat Valenciana DOGV, n 28 de abril de 2014, n7262. v. Retrieved from http://www.dogv.gva.es/es/disposicio? sig=003672/2014\&\&L=1

Comunicación de la Comisión al Parlamento Europeo, al Consejo, al Comité Económico y Social Europeo y al Comité de las Regiones. Infraestructura Verde: mejora del capital natural de Europa. DCOM (2013) 249 final. Bruselas 6.05.2013. Retrieved from https://eurlex.europa.eu/resource.html?uri=cellar:d41348f2-01d5-4abe-b817-

4c73e6f1b2df.0008.03/DOC_ 1\&format=PDF 
Directiva UE 92/43/CEE del Consejo de 21 de mayo de 1992 relativa a la conservación de los hábitats naturales y de la flora y fauna silvestre. Diario Oficial De Las Comunidades Europeas. Retrieved from https://eur-lex.europa.eu/legalcontent/ES/TXT/PDF/?uri=CELEX:31992L0043\&from=EN

Resolución de 20 de noviembre de 2015, de la Dirección General de Sostenibilidad de la Costa y del Mar, por la que se integran en la Red de Áreas Marinas Protegidas de España las zonas de especial protección para las aves marinas de la Red Natura 2000. Boletín Oficial del Estado, 21 de enero de 2016, n¹8. Retrieved from https://www.boe.es/eli/es/res/2015/11/20/(2)

Ley 42/2007, de 13 de diciembre, del Patrimonio Natural y de la Biodiversidad Boletín Oficial del Estado, 14 de diciembre de 2007, $\mathrm{n}^{\circ}$ 299. Retrieved from https://www.boe.es/eli/es/l/2007/12/13/42

Código de Urbanismo de la Comunitat Valenciana, edición actualizada a 3 de julio de 2017. Catálogo de publicaciones de la Administración General del Estado. Boletín Oficial del Estado, Madrid. Retrieved from

https://www.boe.es/legislacion/codigos/codigo.php?id=013_Codigo_de_Urbanismo_de_la_Co $\underline{\text { munidad_Valenciana\&modo }=1}$

Ley 12/2009, de 23 de diciembre de medidas fiscales, de gestión administrativa y financiera, y de organización de la Generalitat. Diario Oficial de la Generalitat Valenciana, 30 de diciembre de 2009, n 6175. Retrieved from

https://www.dogv.gva.es/portal/ficha_disposicion_pc.jsp?sig=014617/2009\&L=1

Ley 11/1994, de 27 de diciembre, de la Generalitat Valenciana, de Espacios Naturales Protegidos de la Comunitat Valenciana. Diario Oficial de la Generalitat Valenciana, 9 de enero de 1995, $n^{\circ}$ 2423. Retrieved from

http://www.dogv.gva.es/portal/ficha_disposicion.jsp?id=24\&sig=0046/1995\&L=1\&url_lista

Decreto 218/1994, de 17 de octubre, del Gobierno Valenciano, por el que se crea la figura de protección de especies silvestres denominada microrreserva vegetal. Diario Oficial de la Generalitat Valenciana, 03 de noviembre de 1994, n'2379. Retrieved from http://www.dogv.gva.es/portal/ficha_disposicion.jsp?id=1694\&sig=2410/1994\&L=1\&url_lista= $\pm$

Resolución de 11 de noviembre de 2015 de la Consellería de Vivienda, Obras Públicas y Vertebración del Territorio por la que se inicia el Plan de Acción Territorial de la Infraestructura Verde del Litoral de la Comunitat Valenciana Diario Oficial de la Generalitat Valenciana, 16 de noviembre de 2015, $n^{\circ} 7658$. Retrieved from http://www.dogv.gva.es/datos/2015/11/16/pdf/2015_9224.pdf 
Resolución de 28 de octubre de 2016, de la Conselleria de Vivienda, Obras Públicas y Vertebración del Territorio, por la que se somete a consultas y participación e información pública, por un periodo de dos meses, la propuesta del Plan de Acción Territorial de la Infraestructura Verde del Litoral de la Comunitat Valenciana Diario Oficial de la Generalitat Valenciana, 11 de noviembre de 2016, no7915. Retrieved from https://www.dogv.gva.es/datos/2016/11/11/pdf/2016_8746.pdf

Resolución de 8 de mayo, de la Consellería de Vivienda, Obras Públicas y Vertebración del Territorio por la que se somete nuevamente a consultas y participación e información pública la Propuesta de Plan de Acción Territorial de la Infraestructura Verde del litoral de la Comunitat Valenciana. Diario Oficial de la Generalitat Valenciana, 19 de mayo de 2017, no 8043. Retrieved from https://www.dogv.gva.es/datos/2017/05/19/pdf/2017_4217.pdf

Decreto 58/2018, de 4 de mayo, del Consell, por el que se aprueba el Plan de Acción Territorial de la Infraestructura Verde del Litoral de la Comunitat Valenciana y el Catálogo de Playas de la Comunitat Valenciana. Diario Oficial de la Generalitat Valenciana, 11 de mayo de 2018, n8293. Retrieved from http://www.dogv.gva.es/portal/ficha_disposicion.jsp?L=1\&sig=004691\%2F2018 